\title{
An Experimental Study on Mixing Induced by Gravity Currents on a Sloping Bottom in a Rotating Fluid
}

by

\author{
Mitchihiro Ohiwa
}

B.S., Earth and Planetary Physics

The University of Tokyo, 2000

Submitted in partial fulfillment of the requirements for the degree of

Master of Science

at the

\section{MASSACHUSETTS INSTITUTE OF TECHNOLOGY}

$$
\begin{gathered}
\text { and the } \\
\text { WOODS HOLE OCEANOGRAPHIC INSTITUTIO }
\end{gathered}
$$

September 2002

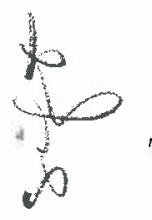
The author hereby grants MIT and WHOI permission to reproduce and to distribute
publicly paper and electronic copies of this thesis document in whole or in part. (c)Mitchihiro Ohiwa, MMII. All rights reserved.

Signature of Author

Joint Program in Physical Oceanography Massachusetts Institute of Technology

Woods Hole Oceanographic Institution September 2002

Certified by

John A. Whitehead Thesis Supervisor

Accepted by

Carl Wunsch Chairman, Joint Committee for Physical Oceanography Massachusetts Institute of Technology 


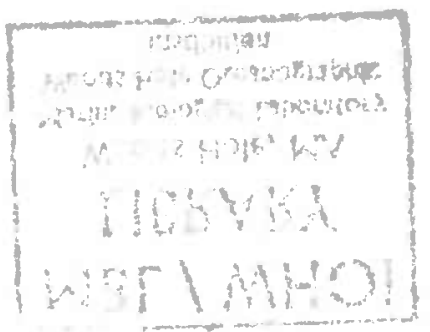




\title{
An Experimental Study on Mixing Induced by Gravity Currents on a Sloping Bottom in a Rotating Fluid
}

\author{
by \\ Mitchihiro Ohiwa \\ Submitted to the Massachusetts Institute of Technology and the Wood Hole \\ Oceanographic Institution in partial fulfillment of the requirements for the degree of \\ Master of Science
}

\begin{abstract}
Mixing induced by gravity currents on a sloping bottom was studied through laboratory experiments in a rotating fluid. The dense fluid on the sloping bottom formed a gravity current that could be in regimes where the flow was laminar or had waves. The mixing on a sloping bottom for gravity currents in the laminar and wave regimes was studied both qualitatively and quantitatively.

The laboratory experiments were conducted on rotating tables in a tank with homogeneous ambient fluid. The slope angle, rotation rate, reduced gravity, and flow rate of the dense source water were changed for the experiments. The mixing was quantized by measuring the density of the ambient fluid, dense source water, and the bottom water collected at the end of the bottom slope and calculating the ratio of the source water in the bottom water.

Comparing the mixing in the laminar regime and the wave regime by changing the slope angle and rotation rate showed that the waves in the gravity current increased the mixing due to the waves. Analysis of the ratio of source water based on the internal Froude number, the Ekman number, and the timescale of the experiments showed that diffusion was not the main mechanism for mixing. The Ekman layer solution was validated by the observation of a streak left by a grain of dye in the dense water layer.

The values for the entrainment parameter for the laboratory experiments bracketed those calculated for the Denmark Strait overflow and the Mediterranean outflow, and the values based on observations in the ocean and those from the laboratory were similar for a nondimensional parameter defined using variables used in the laboratory experiments. This shows that the results from the experiments could be used to discuss the mixing in the ocean due to gravity currents along a slope in the ocean and that the waves observed in the laboratory might also be observed in the ocean.
\end{abstract}

Thesis Supervisor: Dr. John A. Whitehead

Title: Senior Scientist, Woods Hole Oceanographic Institution 


\section{Acknowledgments}

I am grateful of the opportunity that was given to me to study in the MIT/WHOI Joint Program. The course work and research that led to the degree of Master of Science were intellectually challenging and satisfying. Dr. John A. Whitehead kindly offered support and provided guidance at the appropriate times as my advisor, allowing me to make both mistakes and progress in research. Dr. Claudia Cenedese spent time with me introducing references and reviewing the initially perplexing results from the laboratory experiments. Mr. Keith Bradly assisted me with setting up the experiments and shared ideas with me to improve the apparatus and the methods for the experiments. Dr. James F. Price took the time to review the draft of the thesis for me and provided valuable comments.

The research experience prior to thesis research with Dr. David C. Chapman on numerical methods and that with Dr. W. Brechner Owens on float data collected in the South Atlantic Ocean helped broaden my view on oceanography. I appreciate the encouragement I received to enroll in the Joint Program, the assistance I was given to attend a meeting with principal investigators, and the arrangements made for a position on a research cruise in the Arctic Ocean by Dr. David C. Chapman. An opportunity to be on a research cruise in the Gulf of Aden was provided by Dr. David M. Fratantoni, and there was much to be learned about oceanography and research management from Dr. Amy S. Bower during the cruise.

My classmates Shin Kida, J. Tom Farrar, and Jason Hyatt were available to discuss course work, research, and personal issues. I will for long cherish the friendship that formed between us. Discussions with Judith R. Wells and Andrew D. Mosedale were helpful to improving my research.

Timely assistance was provided by the Education Office, Mr. and Mrs. Picciotto, Shelly R. Farrar, and Takami Arafune while I was studying in the Joint Program.

This research was funded by the National Science Foundation, Ocean Sciences Division Grant OCE-0081179. 


\section{Contents}

1 Introduction $\quad 9$

1.1 Overflow and Mixing . . . . . . . . . . . . . 9

1.2 Previous Work . . . . . . . . . . . . . . . . . 13

1.3 Present Work . . . . . . . . . . . . . . . . . . . . . . 16

$\begin{array}{lll}2 & \text { Theory } & 17\end{array}$

3 Experiments 23

3.1 Apparatus . . . . . . . . . . . . . . . . . . 23

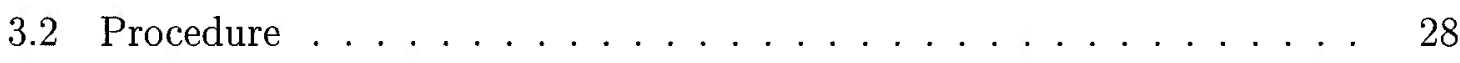

4 Results 31

4.1 Qualitative Description ... . . . . . . . . . . . . . . 31

4.2 Results From the Experiments on the One-meter Rotating Table . . . 32

4.2 .1 Flow Characteristics . . . . . . . . . . . . . . . . 32

4.2 .2 Slope and Mixing . . . . . . . . . . . . . . . 34

4.2 .3 Rotation and Mixing . . . . . . . . . . . . . 36

4.2.4 Flow Rate of Source Water and Mixing . . . . . . . . . 36

4.2 .5 Froude Number and Mixing . . . . . . . . . . . . 42

4.2 .6 Ekman Number and Mixing . . . . . . . . . . . . . . 43

4.2.7 Simple Topography and Mixing . . . . . . . . . . . . 43

4.3 Results From the Experiments on the Two-meter Rotating Table . . . 48 
4.3 .1 Flow Characteristics . . . . . . . . . . . . . . 48

4.3.2 Non-dimensional Numbers and Mixing . . . . . . . . . 49

4.3 .3 Diffusion and Mixing . . . . . . . . . . . . . . . . 54

4.3.4 Ekman Layer in the Flow . . . . . . . . . . . . . 54

4.4 Experiment Data . . . . . . . . . . . . . . . . . . . . 58

5 Summary and Discussion $\quad 61$

5.1 Primary Results . . . . . . . . . . . . . . . . . . . . . . 61

5.2 Comparison of Results . . . . . . . . . . . . . . . . . 64

5.3 Connection to the Ocean . . . . . . . . . . . . . . . 69

5.4 Recommendations. . . . . . . . . . . . . . . . . 73 


\section{Chapter 1}

\section{Introduction}

\subsection{Overflow and Mixing}

The global ocean circulation is a fascinating topic. However, the global ocean circulation consists of various processes that take place on various time scales and length scales, at various locations and depths, at various times and cycles, and it is natural to study the components that comprise the problem to further understand the grand picture of the circulation. The ocean circulation can be divided into the thermohaline and the wind-driven components (Pickard and Emery, 1990). The thermohaline circulation is caused by the changes in the density of sea water, and the understanding of the production and the subsequent transformation of the dense water is integral to the understanding of the thermohaline circulation and the ocean circulation.

The dense water can be formed through the increase in salinity or decrease in temperature. In the high-latitude oceans such as the Greenland Sea and the Antarctic Ocean, freezing or excessive cooling of high-salinity water at the surface can cause density increase in the water column. Ice formation causes brine rejection which increases the salinity of the surrounding water, and excessive cooling decreases the temperature of the surface water. The density of the surface water can increase due to the increase in salinity when there is excess evaporation compared to precipitation 
and run-off. This mechanism takes place in marginal seas such as the Mediterranean Sea and the Red Sea. Whether the density increase of the surface water is due to the increase in salinity or decrease in temperature, vertical convection can develop when the density of the surface water is increased and may bring about the renewal of the bottom water. When the dense water forms in an enclosed sea connected to the open ocean with a sill in between, the dense water formed inside the enclosed sea will have a higher density than the water at the same depth outside the sill and must flow out over the sill following the bottom slope. (Sverdrup et al., 1942)

Figure 1-1 is a schematic drawing of the $\sigma_{4}$ isopycnals based on the data from the Western Atlantic section of the GEOSECS cruises (Bainbridge, 1980). The figure shows that overflow is a phenomenon not restricted to regions with sills near the surface of the ocean, but also taking place over the topography in the deep ocean. The water masses in the ocean could be changing its properties as they experience overflow in the near-quiescent deep ocean.

The dense overflow water mixes with the ambient water and its density decreases as it descends the slope. The overflow water can remain on the slope and reach the end of the slope if it maintains a density that is greater than that of the ambient water even after being modified as it mixes with the ambient water (Figure 1-2a). Observational data show that the North Atlantic Deep Water (NADW) and the Antarctic Bottom Water (AABW) reach the end of the slope and continue to travel along the bottom of the ocean (Bainbridge, 1976). The density of the overflow water will be adjusted to the density of the ambient water and spread along isopycnals if there is sufficient mixing between the overflow water and the ambient water to modify the density of the overflow water (Figure 1-2b). Observational data show that the Mediterranean outflow water adjusts to the environment and then spreads into the Atlantic Ocean (Worthington and Wright, 1970). 


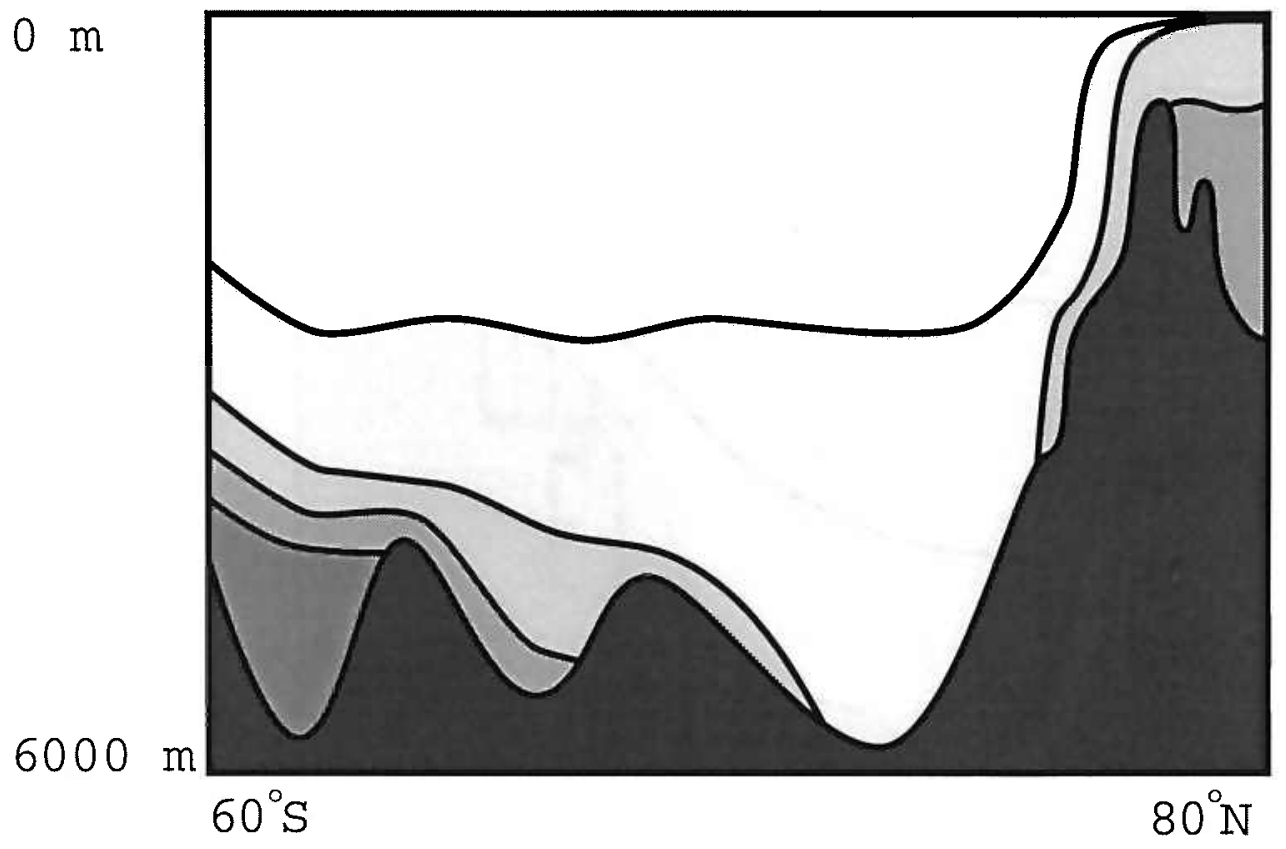

Figure 1-1: A schematic drawing of overflow over topography based on the Western Atlantic $\sigma_{4}$ cross section of the GEOSECS map (Bainbridge, 1980). 'The water with higher density is represented by darker shades. 


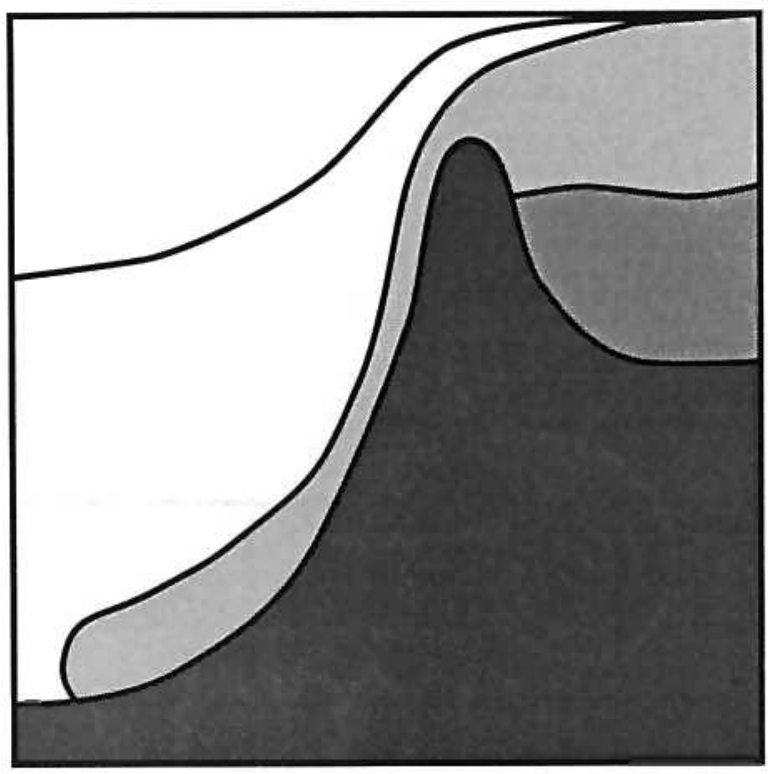

(a)

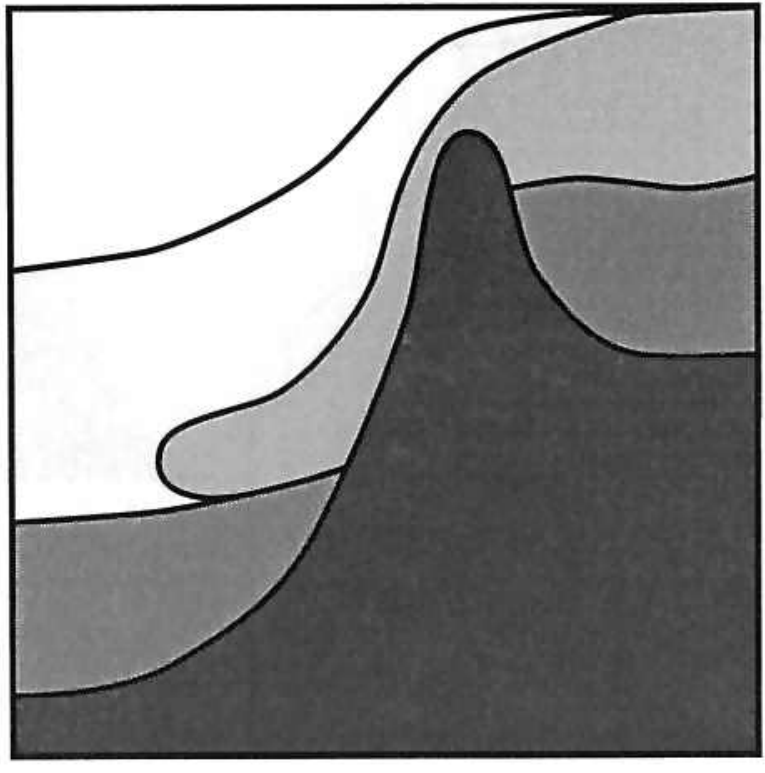

(b)

Figure 1-2: Schematic drawings of dense water overflow. The water with higher density is represented by darker shades. (a) The overflow water has a higher density than the ambient water and reaches the end of the slope. (b) The overflow water adjusts to the ambient water at mid-depth and spreads along an isopycnal. 


\subsection{Previous Work}

The study of overflow progressed when a pioneering work on gravity currents was published by Smith (1975), in which a dynamical streamtube model was developed. The streamtube model assumed a steady flow of well-mixed dense water on a simple slope in a linearly stratified environment, and was used to describe the flow properties of outflow currents, to determine the prominent scales of motion, and to demonstrate the gross interaction among turbulent entrainment, bottom friction, and stratification of the ambient density field.

Studies have been done to include entrainment in the streamtube model. Pedersen (1980) included entrainment as a function of bottom slope, Price and Baringer (1994) attempted to predict the entrainment by functions of flow parameters, and Baringer and Price (1997b) included entrainment as a function of an internal Froude number.

Detailed observational studies on overflow have been done on principal overflows in the ocean. A study on the production of the North Atlantic Deep Water (NADW) by Dickson and Brown (1994) described the downstream evolution of the mean speed, depth, and entrainment of the outflow based on the data obtained from three longterm current meter arrays that were set at up to $160 \mathrm{~km}$ intervals south of the Denmark Strait. It was reported that the volume of the dense overflow water that made up the NADW was initially $5.6 \times 10^{6} \mathrm{~m}^{3} \mathrm{sec}^{-1}$ and increased to $13.3 \times 10^{6} \mathrm{~m}^{3} \mathrm{sec}^{-1}$ after entraining the ambient fluid, where the Denmark Strait Overflow accounted for $2.9 \times 10^{6} \mathrm{~m}^{3} \mathrm{sec}^{-1}$ of the initial overflow and $5.2 \times 10^{6} \mathrm{~m}^{3} \mathrm{sec}^{-1}$ after entrainment. The velocity cross sections along the path of the dense overflow water showed that the fluid decelerated from $60 \mathrm{~cm} \cdot \mathrm{sec}^{-1}$ to $30 \mathrm{~cm} \cdot \mathrm{sec}^{-1}$ and that the contribution of entrainment was most influential in the initial descent of the slope. The Denmark Strait Overflow Water (DSOW) was described as a gravity current lacking seasonal variability in current speed and having energetic fluctuation with a period of a few days and an amplitude similar to that of the mean. The fluctuation seen in the observations was described in Smith (1976) as the development of baroclinic instability 
south of the sill.

Another valuable observational study on overflow was done in the Mediterranean Sea and presented in Baringer and Price (1997a). The data from the CTD (conductivitytemperature-depth) and XCP (expendable current profiler) measurements showed that the overflow was asymmetric with the southern edge of the flow descending more than the northern edge and broadened to $80 \mathrm{~km}$ in width after leaving the $10 \mathrm{~km}$-wide Strait of Gibraltar. The estimate of outflow transport at the western end of the strait was given as $0.7 \times 10^{6} \mathrm{~m}^{3} \mathrm{~s}^{-1}$, of which $0.4 \times 10^{6} \mathrm{~m}^{3} \mathrm{~s}^{-1}$ was Mediterranean source water which was defined as water with salinity higher than 38.4 p.s.u. The XCP profiles showed Ekman spirals at the bottom, but it was also noted that the Ekman veering would not fully account for the spreading rate of the overflow water. It was proposed that mixing might be related to station spans where the Froude number was greater than unity.

Numerical studies have been done with a variety of parameter settings to reproduce the flow in the ocean and illuminate the effects of individual forcing terms connected to the flow. Jiang and Garwood (1996) studied the three-dimensional features and instabilities of dense overflows from marginal seas to continental slopes using a three-dimensional, primitive equation numerical model. It was shown in the numerical experiments of non-rotational plumes that baroclinic instability and bottom friction deformed the dense plume and the instabilities were manifested as roll waves.

Jungclaus and Backhaus (1994) modeled a flow along a slope in a rotating frame and showed the role of bottom friction for bottom-arrested boundary currents and the transient character of bottom boundary currents. It was shown that the balance in the overflow was between bottom friction and the pressure force, that the downslope spreading was enhanced when entrainment was neglected, and that a pronounced head for the plume developed when entrainment parameterized based on the Richardson number was included. 
Results from a numerical study explicitly resolving Kelvin-Helmholtz instability on a gravity current was presented in Özgökmen and Chassignet (2002). The study was done without rotation focusing on the head of the flow. It was shown that entrainment was a function of the buoyancy flux and the slope when the flow was either laminar or had waves. The results from the model runs show the fine velocity structure of the current.

Many laboratory experiments have been done to study gravity currents. In nonrotating settings, the unique and complicated structure of the head of the gravity current has been studied extensively (see Simpson, 1997). Smith (1977) conducted quantitative experiments on flows on a sloping bottom in a rotating frame, and identified that eddies were produced for most of the parameter settings used and that there was a viscous drainage layer.

In a rotating frame, an intriguing eddy formation has often been the focus of the laboratory experiments. However, Whitehead et al. (1990), Lane-Serff and Baines (1998), and Etling et al. (2000) present results from rotating tank experiments that show an eye-catching wave-like feature in the gravity currents. The study by Whitehead et al. (1990) was inspired by the interest in conducting laboratory experiments to bridge between the understanding of isolated eddy structures observed in the ocean and the modon solutions, but gravity currents appear alongside the eddies in some figures (Figures 3 and 7 ). The wave-like feature in the gravity current was speculated to be nonlinearities in the form of roll waves or waves due to Ekman layer instability. Lane-Serff and Baines (1998) noted that the flow was drained downslope in a viscous Ekman layer which may become unstable to growing waves observing the waves on the gravity current (Figure 3). The primary focus of the study done by Etling et al. (2000) was the coupling between the near-surface cyclonic vortices and the density currents, but the waves in the gravity current were clearly visible (Figure 2). 


\subsection{Present Work}

The present study intends to contribute to the understanding of the global ocean circulation through laboratory experiments quantifying the mixing induced by gravity currents on a sloping bottom.

The laboratory experiments simulate the flow of dense water along a slope. The experiments were conducted on a rotating table using a sloping bottom. A source was configured so that it represented a marginal sea containing the dense source water and was attached to the bottom slope.

The waves that appear in a gravity current descending a sloping bottom have been observed in laboratory experiments and numerical experiments, but the effects of the waves on the properties of the gravity current have not been studied in the past. This thesis shows the parameter range within which waves appear in the gravity current and the amount of mixing taking place on the sloping bottom as the current descends the sloping bottom. The mixing was quantified through a parameter $\mathrm{R}$ that measures the ratio of source water in the product water that reached the end of the sloping bottom after experiencing mixing on the sloping bottom.

Mechanical mixing due to the waves in the gravity current was the primary mechanism for determining the values of $R$ in the initial set of experiments using a shorter bottom slope, but the flow regime and $R$ were not related the same way for the set of experiments done on a longer bottom slope. A relation between $R$ and diffusion was found when the sloping bottom had greater length for the dense fluid to descend, but the comparison of the duration of the experiments and the diffusive time scale showed that diffusion was not the primary mechanism for the mixing.

A two-layer model for a laminar flow is shown and solved for in Chapter 2, the apparatus and procedure used in the experiments are described in Chapter 3, the results from the experiments are presented in Chapter 4, and the results are summarized and discussed in Chapter 5. 


\section{Chapter 2}

\section{Theory}

A two-layer model was considered to derive the governing equation for the problem of a gravity current on a sloping bottom following Nagata et al. (1993) and extending it to include the slope angle. A schematic of the problem setting is shown in Figure 2-1. The properties of the upper layer fluid are denoted using the subscript 1 , and the properties of the lower layer fluid are denoted using the subscript 2. The two layers of fluid have uniform densities of $\rho_{1}$ and $\rho_{2}$, and the lower layer has a higher density than the upper layer $\left(\rho_{1}<\rho_{2}\right)$. The layer thickness of the lower layer is $h$. With the origin at the upper right corner of the slope, the $x$-axis is taken positive to the right looking at the top of the slope from the bottom, the $y$-axis is taken positive along the slope in the up-slope direction, and the $z$-axis is taken positive upward vertical to the slope. The axes are taken in this manner because the shallow side of the tank is dynamically equivalent to the north on the earth for the northern hemisphere in laboratory experiments with a sloping bottom. The slope makes an angle $\theta$ with the horizontal surface.

The momentum equation for a fluid parcel in a rotating tank is written

$$
\frac{d \vec{u}}{d t}+2 \vec{\Omega} \times \vec{u}=-\frac{1}{\rho} \nabla p+\vec{F},
$$




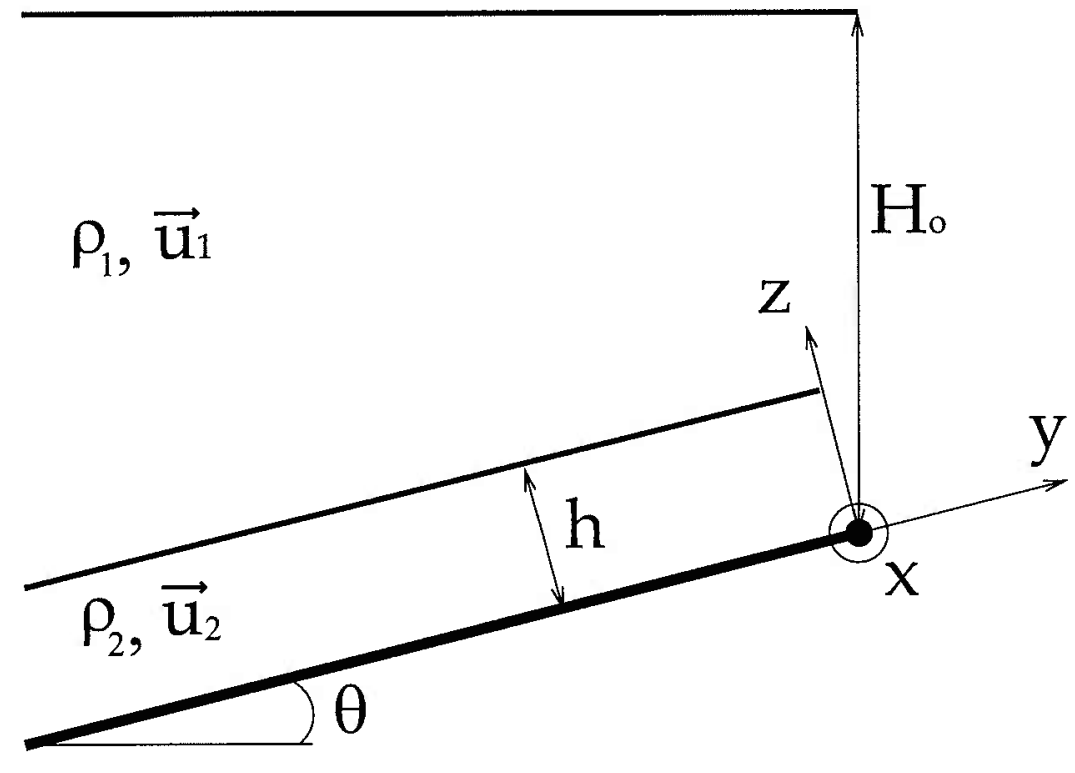

Figure 2-1: A schematic of the setting of the two-layer fluid. The properties of the fluid for the upper and lower layers are denoted using the subscripts 1 and 2, respectively. The angle between the sloping bottom and the bottom of the tank is $\theta$, and the lower layer has a thickness of $h$. 
where $\vec{u}, \Omega, \rho, p$, and $\vec{F}$ denote velocity, rotation of the tank, density, pressure, and external forcing, respectively. Assuming a linear steady state and including the gravitational forcing and lateral friction for the forcing term $(\vec{F})$, eq. $(2.1)$ becomes

$$
\rho=2 \vec{\Omega} \times \vec{u}=-\nabla p+\mu \frac{\partial^{2} \vec{u}}{\partial z^{2}}+\rho \vec{g},
$$

where $\mu$ and $\vec{g}$ denote dynamic viscosity and gravity, respectively.

Taking the reference pressure as $p_{0}$ at the surface of the upper layer, the hydrostatic pressure at a point $(x, y, z)$ in the upper layer $\left(p_{1}\right)$ and in the lower layer $\left(p_{2}\right)$ can be written

$$
\begin{aligned}
& p_{1}=p_{o}+\rho_{1} g\left[H_{o}-y \sin \theta-z \cos \theta\right] \\
& p_{2}=p_{o}+\rho_{1} g\left[H_{\circ}-y \sin \theta+z \frac{\sin ^{2} \theta}{\cos \theta}-\frac{h}{\cos \theta}\right]+\rho_{2} g \frac{h-z}{\cos \theta},
\end{aligned}
$$

Assuming a constant $h$ for a linear flow and substituting eqs.(2.3) and (2.4) into eq.(2.2), the $x$ - and $y$-components of the momentum equation are written for the upper layer as

$$
\begin{aligned}
-f^{*} v_{1} & =v \frac{\partial^{2} u_{1}}{\partial z^{2}} \\
f^{*} u_{1} & =v \frac{\partial^{2} v_{1}}{\partial z^{2}}
\end{aligned}
$$

and for the lower layer as

$$
\begin{aligned}
-f^{*} v_{2} & =v \frac{\partial^{2} u_{2}}{\partial z^{2}} \\
f^{*} u_{2} & =v \frac{\partial^{2} v_{2}}{\partial z^{2}}-g^{\prime} \sin \theta
\end{aligned}
$$

where $f^{*}$ is defined as $f^{*}=2 \Omega \cos \theta, \nu$ is the kinematic viscosity defined as $\nu=\mu / \rho$, and $g^{\prime}$ is the reduced gravity defined as $g^{\prime}=g\left(\rho_{2}-\rho_{1}\right) / \rho_{1}$. The difference in the 
equations for the two layers is the second term on the r.h.s. of eq.(2.8). This term arises due to the density difference between the two layers. The pressure gradient and the gravitational forcing balance each other in the upper layer and in the $x$-direction in the lower layer.

The boundary conditions imposed on this system are that each of the velocity components are set to zero on the surface of the sloping bottom, that they approach zero as $z$ becomes far away from the interface between the two layers, and that the velocity profiles connect smoothly at the interface of the two layers. These conditions are expressed as

$$
\begin{aligned}
& u_{1}, v_{1} \rightarrow 0 \text { as } z \rightarrow \infty \text {, } \\
& u_{2}, v_{2}=0 \text { at } z=0 \text {, } \\
& u_{1}=u_{2}, v_{1}=v_{2}, \frac{\partial u_{1}}{\partial z}=\frac{\partial u_{2}}{\partial z}, \frac{\partial v_{1}}{\partial z}=\frac{\partial v_{2}}{\partial z} \quad \text { at } \quad z=h \text {. }
\end{aligned}
$$

Under these conditions, the solutions for the velocity components of the two layers are written using $\delta_{E}=\sqrt{2 v / f^{*}}$ and $G_{o}=\frac{g^{\prime} \sin \theta}{2 f^{*}}$ as

$$
\begin{aligned}
u_{1}= & G_{\circ}\left[\left\{1-\frac{1}{2}\left(e^{(1+i) h / \delta_{E}}+e^{-(1+i) h / \delta_{E}}\right)\right\} e^{-(1+i) z / \delta_{E}}\right. \\
& \left.+\left\{1-\frac{1}{2}\left(e^{(1-i) h / \delta_{E}}+e^{-(1-i) h / \delta_{E}}\right)\right\} e^{-(1-i) z / \delta_{E}}\right] \\
= & G_{0} e^{-z / \delta_{E}}\left[2 \cos \left(z / \delta_{E}\right)-e^{h / \delta_{E}} \cos \left(\frac{z-h}{\delta_{E}}\right)-e^{-h / \delta_{E}} \cos \left(\frac{z+h}{\delta_{E}}\right)\right], \\
v_{1}= & -i G_{\circ}\left[\left\{1-\frac{1}{2}\left(e^{(1+i) h / \delta_{E}}+e^{-(1+i) h / \delta_{E}}\right)\right\} e^{-(1+i) z / \delta_{E}}\right. \\
& \left.-\left\{1-\frac{1}{2}\left(e^{(1-i) h / \delta_{E}}+e^{-(1-i) h / \delta_{E}}\right)\right\} e^{-(1-i) z / \delta_{E}}\right] \\
= & -G_{\circ} e^{-z / \delta_{E}}\left[2 \sin \left(z / \delta_{E}\right)-e^{h / \delta_{E}} \sin \left(\frac{z-h}{\delta_{E}}\right)-e^{-h / \delta_{E}} \sin \left(\frac{z+h}{\delta_{E}}\right)\right], \\
u_{2}= & G_{\circ}\left[\frac{1}{2} e^{-(1+i) h / \delta_{E}} \cdot e^{(1+i) z / \delta_{E}}+\frac{1}{2} e^{-(1-i) h / \delta_{E}} \cdot e^{(1-i) z / \delta_{E}}\right.
\end{aligned}
$$




$$
\begin{aligned}
& \left.+\left\{1-\frac{1}{2} e^{-(1+i) h / \delta_{E}}\right\} e^{-(1+i) z / \delta_{E}}+\left\{1-\frac{1}{2} e^{-(1-i) h / \delta_{E}}\right\} e^{-(1-i) z / \delta_{E}}-2\right] \\
= & G_{\circ}\left[e^{-z / \delta_{E}} \cdot 2 \cos \left(z / \delta_{E}\right)\right. \\
& \left.+e^{(z-h) / \delta_{E}} \cdot \cos \left(\frac{z-h}{\delta_{E}}\right)-e^{-(z+h) / \delta_{E}} \cdot \cos \left(\frac{z+h}{\delta_{E}}\right)-2\right] \\
v_{2}= & -i G_{\circ}\left[\frac{1}{2} e^{-(1+i) h / \delta_{E}} \cdot e^{(1+i) z / \delta_{E}}-\frac{1}{2} e^{-(1-i) h / \delta_{E}} \cdot e^{(1-i) z / \delta_{E}}\right. \\
& \left.+\left\{1-\frac{1}{2} e^{-(1+i) h / \delta_{E}}\right\} e^{-(1+i) z / \delta_{E}}-\left\{1-\frac{1}{2} e^{-(1-i) h / \delta_{E}}\right\} e^{-(1-i) z / \delta_{E}}\right] \\
= & -G_{0}\left[e^{-z / \delta_{E}} \cdot 2 \sin \left(z / \delta_{E}\right)\right. \\
& \left.-e^{(z-h) / \delta_{E}} \cdot \sin \left(\frac{z-h}{\delta_{E}}\right)-e^{-(z+h) / \delta_{E}} \cdot \sin \left(\frac{z+h}{\delta_{E}}\right)\right]
\end{aligned}
$$

These results from eq.(2.9) through (2.12) are plotted in Figure 2-2 with a parameter combination used in an experiment. Figures $2-2 \mathrm{a}-\mathrm{c}$ show the vertical profile of the velocity making a spiral. Figure $2-2 d$ shows a top view of the velocity profile that suggests a deflection of the dense fluid in the tank.

Mechanical mixing is caused by the vertical velocity $(w)$ at the interface of the two layers. However, the vertical velocity is defined as $w=\frac{\mathrm{dh}}{\mathrm{dt}}$ and because the layer thickness $(h)$ is taken to be constant here, $w$ is zero by definition. Some form of solution which includes $w$ could be derived using the shallow water approximation, but the amplitude of the waves at the interface in the experiments are comparable to the thickness of the lower layer and the nonlinear components will be important. The shallow water equation assumes the free surface variation to be small compared to the total fluid depth, but in the tank the two are comparable. 

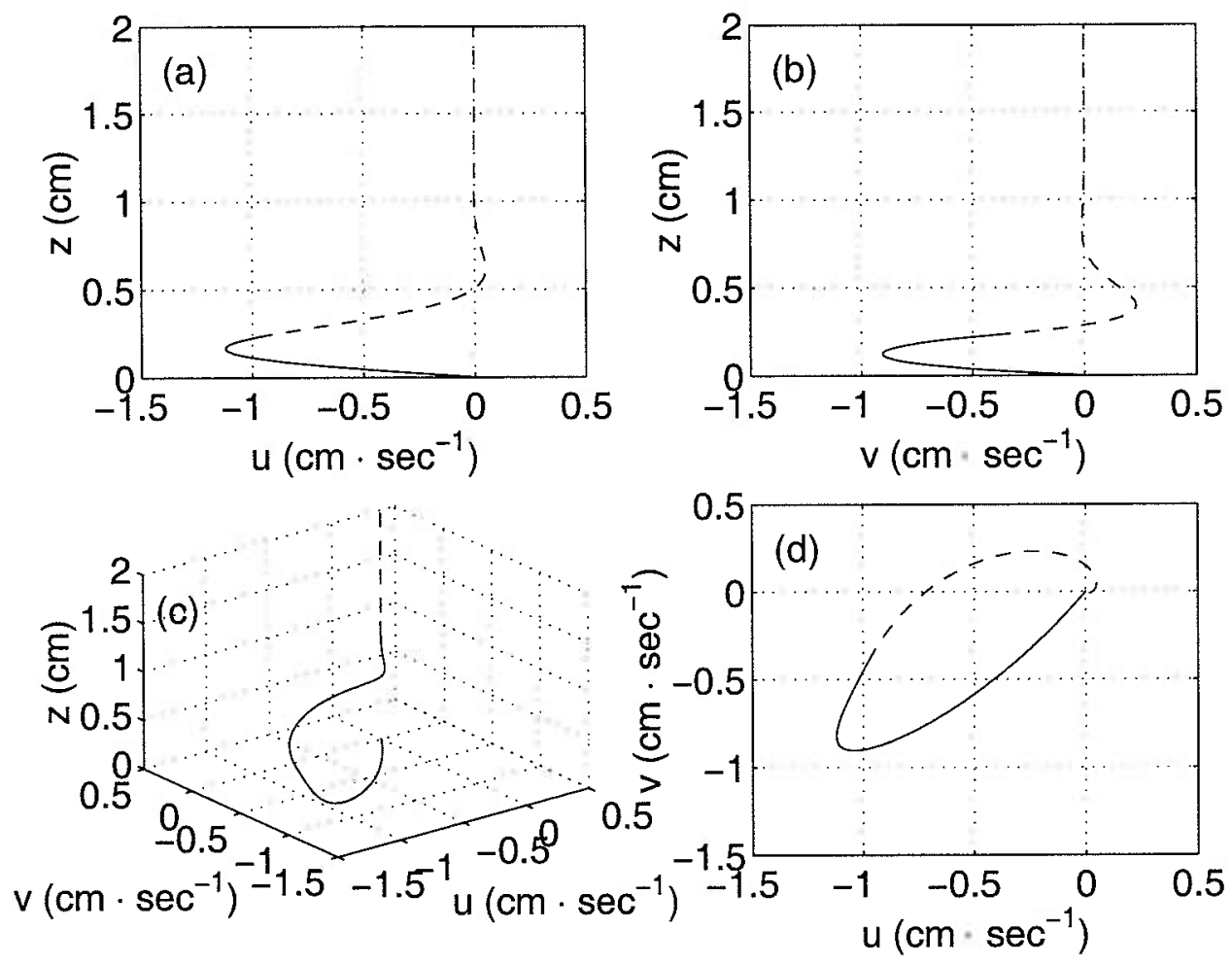

Figure 2-2: Plots made based on the solutions for the (a) vertical profile of the $x$ component of the velocity (u), (b) vertical profile of the $y$-component of the velocity $(v),(c)$ vertical profile of the velocity vector $(\vec{u})$, and (d) top-view of the velocity profile. The parameters used to make these plots were $f=1.0 \mathrm{sec}^{-1}, \mathrm{~g}^{\prime}=10.1 \mathrm{~cm}$. $\sec ^{-2}, s=0.2$, and $h=0.23 \mathrm{~cm}$. The solid line and the dotted line show the velocity profile within the bottom layer and the upper layer, respectively. 


\section{Chapter 3}

\section{Experiments}

\subsection{Apparatus}

Laboratory experiments were done to study the mixing on a sloping bottom induced by gravity currents. The apparatus was configured in a way that it would model the flow of dense water on a sloping bottom in the ocean. The experiments were conducted in a rotating tank with a sloping bottom and a source that represented a source of dense water in the ocean. The dense source water was pumped into the fresh ambient water and then descended the slope.

Two rotating tables and two bottom slopes of different lengths were used. A few sets of experiments were conducted using a bottom slope $58 \mathrm{~cm}$ in length, where waves induced by gravity currents were observed on the sloping bottom, and then a longer bottom slope $(110 \mathrm{~cm})$ was used to allow waves to develop taking longer time.

The tables were rotated counter-clockwise unless noted otherwise, and one had a diameter of $1 \mathrm{~m}$ and the other had a diameter of $2 \mathrm{~m}$. Figure 3-1 shows the sideview and top-view of the setting of the tank for the two-meter rotating table. The one-meter rotating table had the same configuration except for the size and shape of the tank and the length of the bottom slope. For the experiments on the one-meter rotating table, a clear square tank with the dimension of $60 \mathrm{~cm} \times 60 \mathrm{~cm} \times 60 \mathrm{~cm}$ 


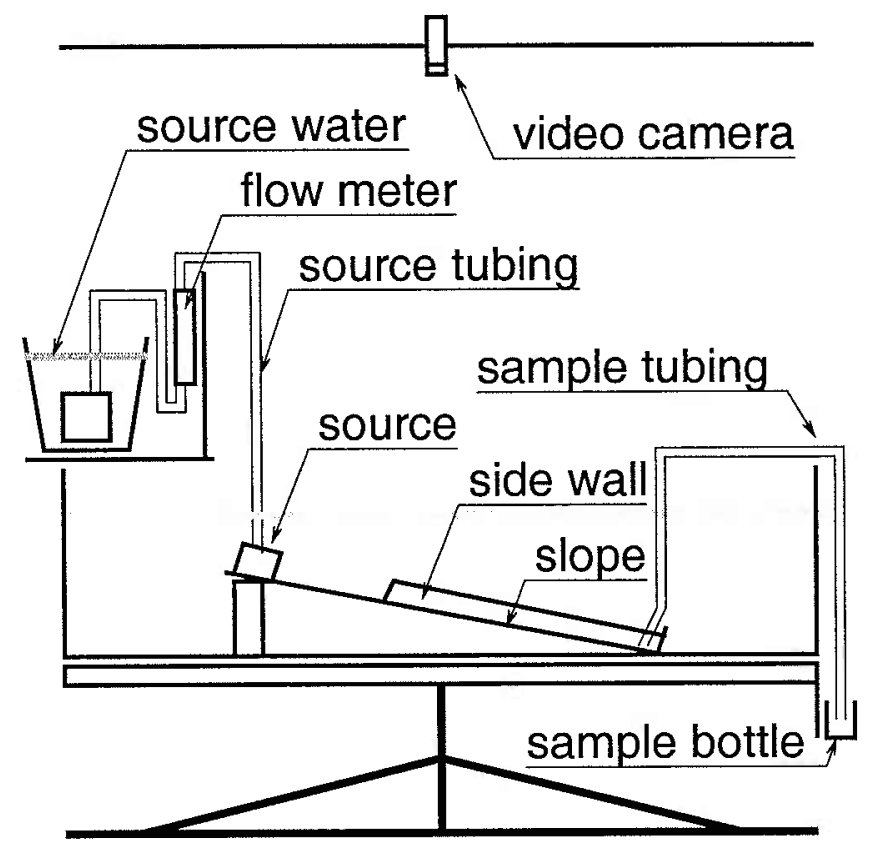

(a)

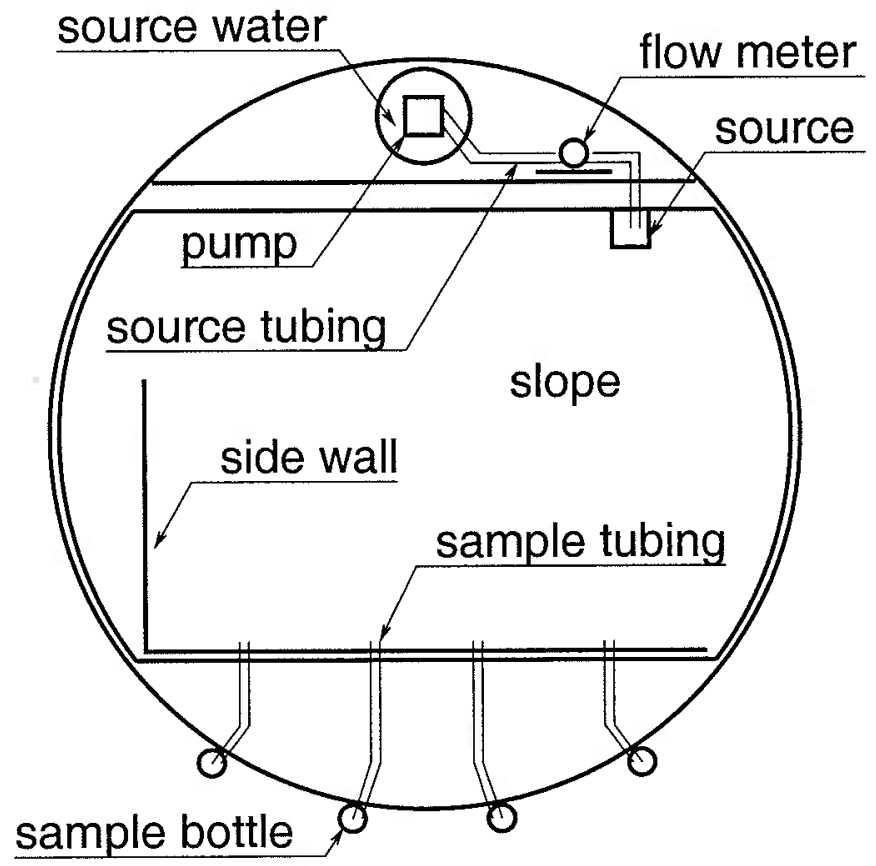

(b)

Figure 3-1: Schematic diagrams of the laboratory setting for the two-meter rotating table. The (a) side-view and (b) top-view are shown. The one-meter rotating table had the same configuration except for the size and shape of the tank and the length of the bottom slope. 
(WDH) was used with an $8 \mathrm{~mm}$ thick Plexiglas board painted white as the bottom slope. The bottom slope was $55 \mathrm{~cm}$ wide and $58 \mathrm{~cm}$ long with $5 \mathrm{~cm}$-high side walls added around the bottom slope using clear plastic to collect the source water that reached the bottom end of the sloping bottom. A video camera was mounted on top of the frame attached to the rotating table to record the experiments. Pictures were taken from the side of the tank during the experiments.

A cylindrical tank $45 \mathrm{~cm}$-deep made of fiberglass with a $2 \mathrm{~m}$-diameter was used for the experiments on the two-meter rotating table. A wood board painted white was used as the bottom slope. The bottom slope had two opposite sides with arcs and two opposite sides that were cut straight. The widest part of the bottom slope was $2 \mathrm{~m}$, the narrowest part was $1.6 \mathrm{~m}$, the length was $110 \mathrm{~cm}$, and the arced edges of the bottom slope matched the curve of the wall of the tank. A plastic wall $5 \mathrm{~cm}$ in height was attached at the end of the bottom slope to collect the dense water when it reached the bottom. The experiments were recorded using a video camera that was mounted above the tank and rotated at the same rate as the table. The flow on the sloping bottom could be observed only from above the tank for the experiments done on the two-meter rotating table.

Whichever table was being used, a salt water source was attached to the shallow end of the bottom slope and the bottom slope was placed in the tank. The slope is defined as $s=\tan \theta$, where $\theta$ is the angle the sloping bottom makes with the bottom of the tank. The tank was filled with filtered fresh water up to $10 \mathrm{~cm}$ above the top of the sloping bottom when $\mathrm{s}$ was less than 0.6 , and up to $5 \mathrm{~cm}$ above the top of the sloping bottom when $s$ was and greater than 0.6. The sloping bottom covered the area of the experiment so it does not matter whether the tank is round or square. A bucket was set on the rim of the rotating table or the tank and contained the dense source water. The source water was made by adding salt to filtered fresh water and coloring it with dye to visualize the flow of the dense fluid. A hydraulic pump was used to pump the dense source water into the tank, and a flow meter was used to 
adjust the flow rate. The hydraulic pump was submerged in the source water in the bucket, and the plastic tubes connected the pump, flow meter, and source on the sloping bottom.

A source was attached to the top of the sloping bottom in the "northeast" ${ }^{1}$ corner and the source water went through this source before descending the sloping bottom. The northeast position was chosen so that the dense fluid will cover the sloping bottom as much as possible while being deflected due to rotation. For the initial experiments on the one-meter table the source was made by placing another piece of clear Plexiglas board on the sloping bottom leaving a $5 \mathrm{~mm}$ gap between the two and making a confined space using two sponge pieces cut to fit the gap (Source A). Source A was used for the experiments described in Section 4.2 except for those described in Subsection 4.2.4. The opening made by the sponge pieces was adjusted so that there would be no turbulence at the source that could cause extra mixing when the flow rate of $2.5 \mathrm{~cm}^{3} \cdot \mathrm{sec}^{-1}$ was used. The source was modified to reduce the mixing before the dense water reached the sloping bottom and so that different flow rates could be used (Source B, Figure 3-2). Source B had a $6 \mathrm{~cm} \times 2.5 \mathrm{~cm} \times 2.5 \mathrm{~cm}$ (WDH) cell where the source water entered, a $3 \mathrm{~mm}$ opening across the width of the source where the source water went through, and a $6 \mathrm{~cm} \times 2.5 \mathrm{~cm} \times 0.5 \mathrm{~cm}(\mathrm{WDH})$ pocket where a sponge piece was placed to reduce inertia of the dense source water as it came through the opening. The top of the sponge was level with the surface of the sloping bottom. Source B could be used with flow rates up to $7.5 \mathrm{~cm}^{3} \cdot \mathrm{sec}^{-1}$ for rotation rates up to $1.5 \mathrm{sec}^{-1}$ and up to $12 \mathrm{~cm}^{3} \cdot \mathrm{sec}^{-1}$ for rotation rates below 0.25 $\mathrm{sec}^{-1}$. The upper limit to the flow rate was different depending on the rotation rate because when the rotation rate was higher the dense water formed eddies and the did not flow down the sloping bottom to form a gravity current. Source B was used for all the experiments on the two-meter rotating table described in Section 4.3 and

\footnotetext{
${ }^{1}$ The term "northeast" is used because the shallower side in a rotating tank with a sloping bottom is dynamically equivalent to north on the northern hemisphere of the earth. (Pedlosky, 1986)
} 


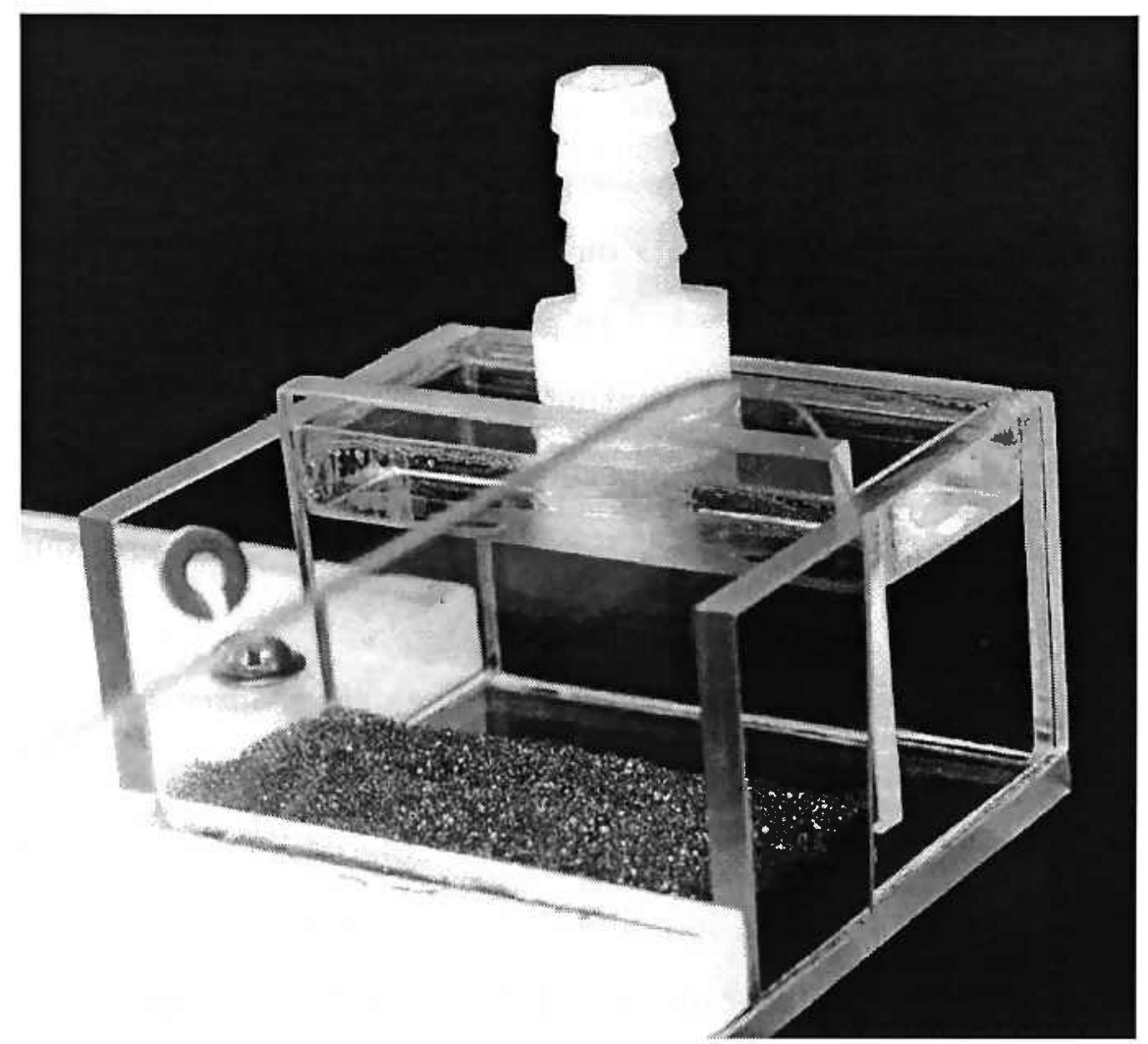

Figure 3-2: A photograph of Source B. The source was attached to the bottom slope. The source water was pumped through the tubing connected to the white connector at the top of the source, went through the cell in the back, the gap at the bottom, and the sponge, and flowed onto the bottom slope. 
the experiments on the one-meter rotating table described in Subsection 4.2.4 where mixing depending on the flow rate of the source water was studied.

\subsection{Procedure}

The tank was spun up before the dense source water was pumped into the tank. The spin-up time $\left(T_{s}\right)$ was calculated from $T_{s}=H_{t} / \sqrt{2 v f}$, where $H_{t}, v$, and $f$ denote the total depth of the ambient fluid, viscosity, and Coriolis parameter, respectively (Pedlosky, 1986). For the experiments on the one-meter rotating table the tank was let to spin up for over 30 minutes before pumping the dense source water onto the sloping bottom. For the two-meter rotating table the tank was let to spin up for over one hour, and for two hours for the experiments with the setting $f=0.25 \mathrm{sec}^{-1}$. The spin-up time was taken longer than the theoretical value based on previous experience with the tanks.

After the spin-up the pump was started and the dense source water went through the source, entered the tank, and descended the sloping bottom. The dense water that reached the end of the sloping bottom accumulated in the pocket made by the walls and was collected using a siphoning method. This water that accumulated at the bottom end of the sloping bottom will be referred to as the "bottom water." Surgical tubes were used for the siphoning, where one end of the tube was attached to the plastic wall at the end of the bottom slope so that the tip of the tube will be covered by the bottom water and the other end hung from the side of the tank with its tip in a sample bottle. The tip in the tank was fixed to the bottom slope so that it will not move and cause mixing at any time during the sampling. The tubing used for the siphoning had air blown through it using a syringe before spinning up the tank. The siphoning was started by extracting the fluid using a syringe after enough bottom water accumulated and the tip of the tube was covered in colored water, and then the bottom water was left to drip into the sample bottle attached to the frame 
of the rotating table. The tip of the sampling tube was attached to the bottom wall where the head of the gravity current hit the bottom. This was at the center at the end of the sloping bottom for experiments with $f=0.25 \mathrm{sec}^{-1}$ and at the bottom-left corner of the bottom end of the sloping bottom for experiments with higher $f$. For the experiments on the two-meter rotating table the sampling tubes were attached to the wall at the bottom of the sloping bottom at four locations along the bottom, and the bottom water was sampled using the tube that had its tip closest to where the head of the gravity current reached. After sampling a few milliliters of water in the sample bottle the water was thrown out because it could contain fresh water that came into the tubing during the spin-up of the tank, and then the bottom water was left to drip into a new sample bottle to be collected as a sample.

The density of the ambient water $\left(\rho_{\mathrm{a}}\right)$, source water $\left(\rho_{\mathrm{s}}\right)$, and bottom water $\left(\rho_{\mathrm{b}}\right)$ was measured to the fifth decimal point using an Anton PAAR DMA 58 digital density meter. The ratio of source water in the bottom water $(R)$ was calculated after the density measurements using

$$
R=\frac{\rho_{\mathrm{b}}-\rho_{\mathrm{a}}}{\rho_{\mathrm{s}}-\rho_{\mathrm{a}}}
$$

The parameter $\mathrm{R}$ is used as an indication for mixing throughout this thesis. A high value for $R$ indicates that there was less mixing on the sloping bottom as the source water descended the sloping bottom, and a low value for $R$ indicates that there was more mixing on the sloping bottom.

There were four independent parameters in the experiments that could be adjusted. The slope (s) was changed by adjusting the length of the string holding up the sloping bottom for the experiments on the one-meter rotating table, and set to 0.2 using a wood block for the experiments on the two-meter rotating table. The upper limit for $s$ was set by the depth of the tank and was 0.7 , and the lower limit was 0.1 . The rotation rate (f) was changed from 0 to $2.0 \mathrm{sec}^{-1}$ with $1 \%$ accuracy. The reduced gravity $\left(\mathrm{g}^{\prime}\right)$ was adjusted between 2 and $35 \mathrm{~cm} \cdot \mathrm{sec}^{-2}$ by changing the amount of salt added to the filtered fresh water to match the desired value calculated 
from

$$
\mathrm{g}^{\prime}=\frac{\rho_{\mathrm{s}}-\rho_{\mathrm{a}}}{\rho_{\mathrm{a}}} .
$$

Formally, the denominator in eq. (3.2) should be the average density of the fluid in the tank, but the difference is less than $1 \%$ at the end of the experiments even when there is the greatest amount of dense fluid in the tank after the experiments. The flow rate (Q) was set to a single value between 1.1 and $12.2 \mathrm{~cm}^{3} \cdot \mathrm{sec}^{-1}$ for each experiment and the flow meter was adjusted during the experiments so that $\mathrm{Q}$ remained constant throughout the experiment.

The video recording was started before the source water was started to be pumped into the tank. The recording was stopped when sufficient amount of bottom water for density measurement was siphoned out into the sample bottle. Recording time for the experiments was 8 to 12 minutes, and the video recording was later analyzed to obtain quantitative results, such as the velocity of the fluid and the area the fluid covered on the sloping bottom. Photographs of the flow of the dense water were taken during the 8 to 12 minutes the dense fluid was being pumped on to the sloping bottom. 


\section{Chapter 4}

\section{Results}

\subsection{Qualitative Description}

The qualitative characteristics of the flow are described in this section. The dense source water was pumped through the source tubing, while the flow rate was adjusted using the flow meter. The dense water went through the source, which was attached to the upper-right corner of the sloping bottom, that had been designed to reduce the mixing of the source water with the ambient water before reaching the sloping bottom. The source water started to descend the sloping bottom because it had a higher density than the fresh ambient water, and the fluid was deflected because the tank was being rotated. The fluid was deflected more and covered a larger area of the sloping bottom when the rotation rate $(f)$ was larger, reduced gravity $\left(g^{\prime}\right)$ was smaller, flow rate $(\mathrm{Q})$ was larger, and slope (s) was larger. The source water experienced mixing as it descended the sloping bottom, and this mixed water reached the end of the sloping bottom and was collected as the bottom water. The flow was laminar (Figure 4-1a) or there were waves (Figure 4-1b) depending on the parameter setting, and wave crests deformed and the waves started to break (Figure 4-1c) when the downslope component of the was velocity increased. A flow was noted as laminar when the dense water descended the sloping bottom without showing any sign of 
perturbation. The head of the lower layer fluid rolled up in a laminar flow, but the fluid behind the head showed no difference in thickness that was observable to the eye. A flow was noted to be in the wave regime when the dense water descending the sloping bottom showed observable difference in layer thickness. The difference in thickness was observable because the color of the bottom layer was darker when the layer was thicker and the color was lighter when the layer was thinner. The term "wave regime" is used because the dark and light parts of the fluid made a wave pattern. The waves became more vigorous and were observed to break as the downslope component of the velocity became greater.

\subsection{Results From the Experiments on the One- meter Rotating Table}

\subsubsection{Flow Characteristics}

The results from the experiments on the one-meter rotating table are described in this section. For most of the experiments, the reduced gravity $\left(g^{\prime}\right)$ was set to $4 \mathrm{~cm} \cdot \mathrm{sec}^{-2}$ and the flow rate (Q) was set to $2.5 \mathrm{~cm}^{3} \cdot \mathrm{sec}^{-1}$, while the slope (s) was changed between 0.1 and 0.7 and the rotation rate (f) was changed between 0 and $2.0 \mathrm{sec}^{-1}$.

Depending on the parameter setting, the dense fluid took 48 to 113 seconds before it hit the western boundary or the bottom end of the sloping bottom. The dense fluid spread out being affected by the rotation, and the area the dense fluid covered on the sloping bottom changed by $20 \%$ over all the experiments. The ratio of source water (R) ranged between 0.63 and 0.99 . When $s$ was greater than 0.4 and $f$ was less than 1.0 and the flow was in the wave regime, higher $s$ caused the waves to break.

The dependence of mixing, indicated by $R$, on individual parameters is described, and then the relation of the results to non-dimensional parameters, the internal Froude number and Ekman number, is studied. 


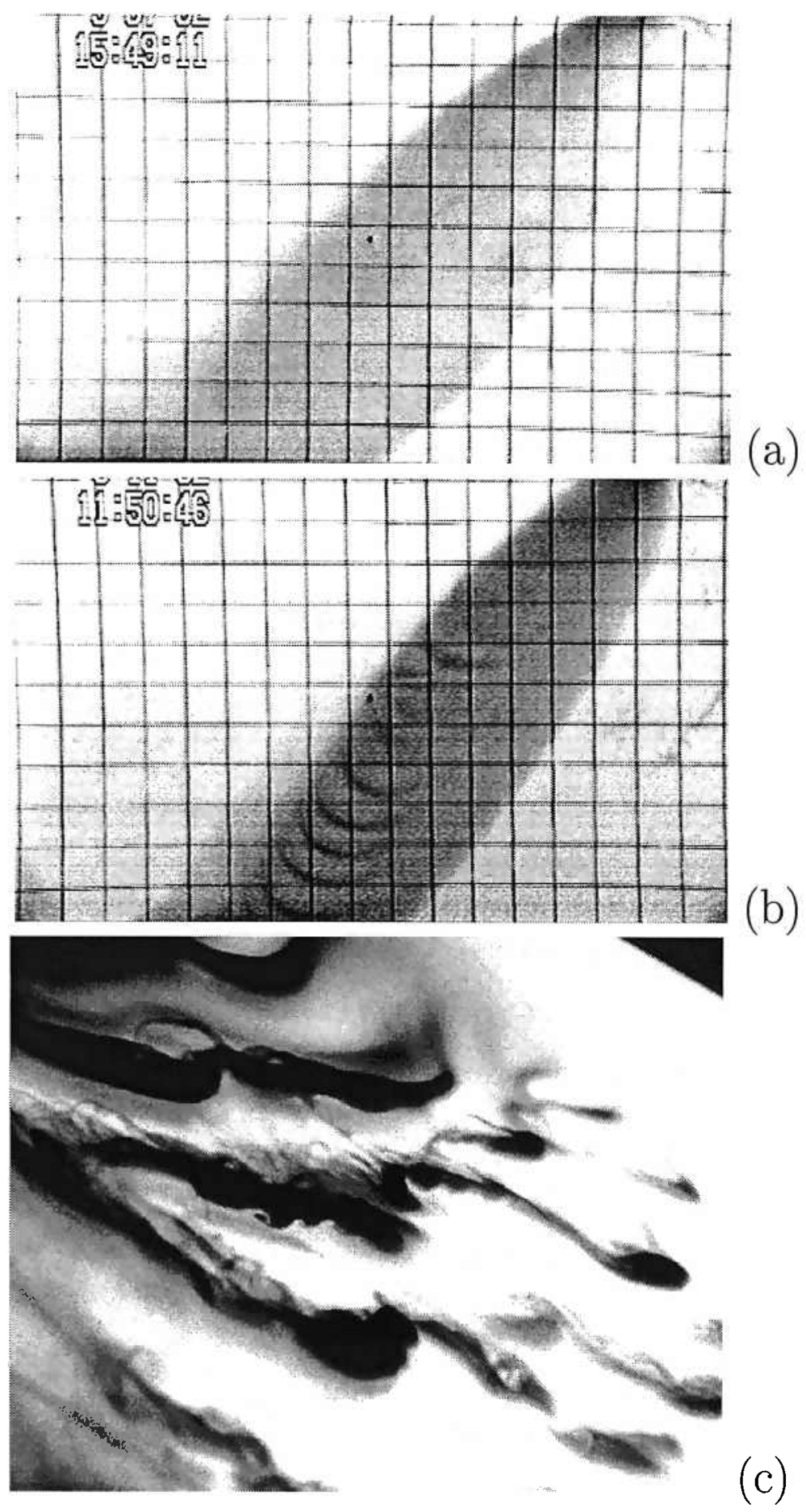

Figure 4-1: The flow pattern of the dense source water on the sloping bottom. The flow can be in a (a) laminar regime or (b) wave regime depending on the parameter settings. The waves break (c) when the downslope component of the velocity becomes greater. 


\subsubsection{Slope and Mixing}

Experiments were done to identify the difference in mixing depending on the regime of the flow. When the slope (s) was small the flow was in the laminar regime, and when $s$ was large the flow was in the wave regime, so to study the mixing depending on the flow regime, $s$ was changed from 0.1 to 0.7 while setting the rotation rate ( $f$ ), reduced gravity $\left(g^{\prime}\right)$, and flow rate $(Q)$ constant at $f=1.0 \mathrm{sec}^{-1}, g^{\prime}=4 \mathrm{~cm} \cdot \mathrm{sec}^{-2}$, and $\mathrm{Q}=2.5 \mathrm{~cm}^{3} \cdot \mathrm{sec}^{-1}$. The results from these experiments are shown in Figure 4-2. The flow was in the laminar regime when $s$ was less than 0.35 , and the ratio of source water $(R)$ changed 0.02 between $s=0.1$ and 0.35 . The flow was in the wave regime when $s$ was greater than 0.4 , and $R$ dropped from 0.96 at $s=0.4$ to 0.63 at $s=0.7$. The waves were breaking when $s$ was higher than 0.5. The increment for $s$ for the experiments were 0.5 when the flow was in the laminar regime and 0.25 when the flow was in the wave regime. The increment for $s$ was made smaller for the flow in the wave regime because the drop in $R$ was greater.

At these parameter settings the flow was deflected westward and came into contact with the western boundary before arriving at the bottom end of the sloping bottom, necessitating the clarification whether the mixing was caused by the flow on the sloping bottom or along the boundary. The mixing for the flow along the boundary was studied by measuring $R$ for the experiments where the table was rotated in the opposite direction (clockwise) so that the flow became a boundary current flowing along only the right-hand boundary without spreading on the sloping bottom. The results from these experiments are plotted in Figure 4-2. Although Figure 4-2 shows that there was mixing even when the flow was only along the boundary, the mixing caused by the flow along the boundary calculated from the difference in $\mathrm{R}$ between the two sets of experiments showed in Figure 4-2 accounts for 16 to $27 \%$ of the total mixing. This shows that mixing primarily took place on the sloping bottom and not along the boundary. 


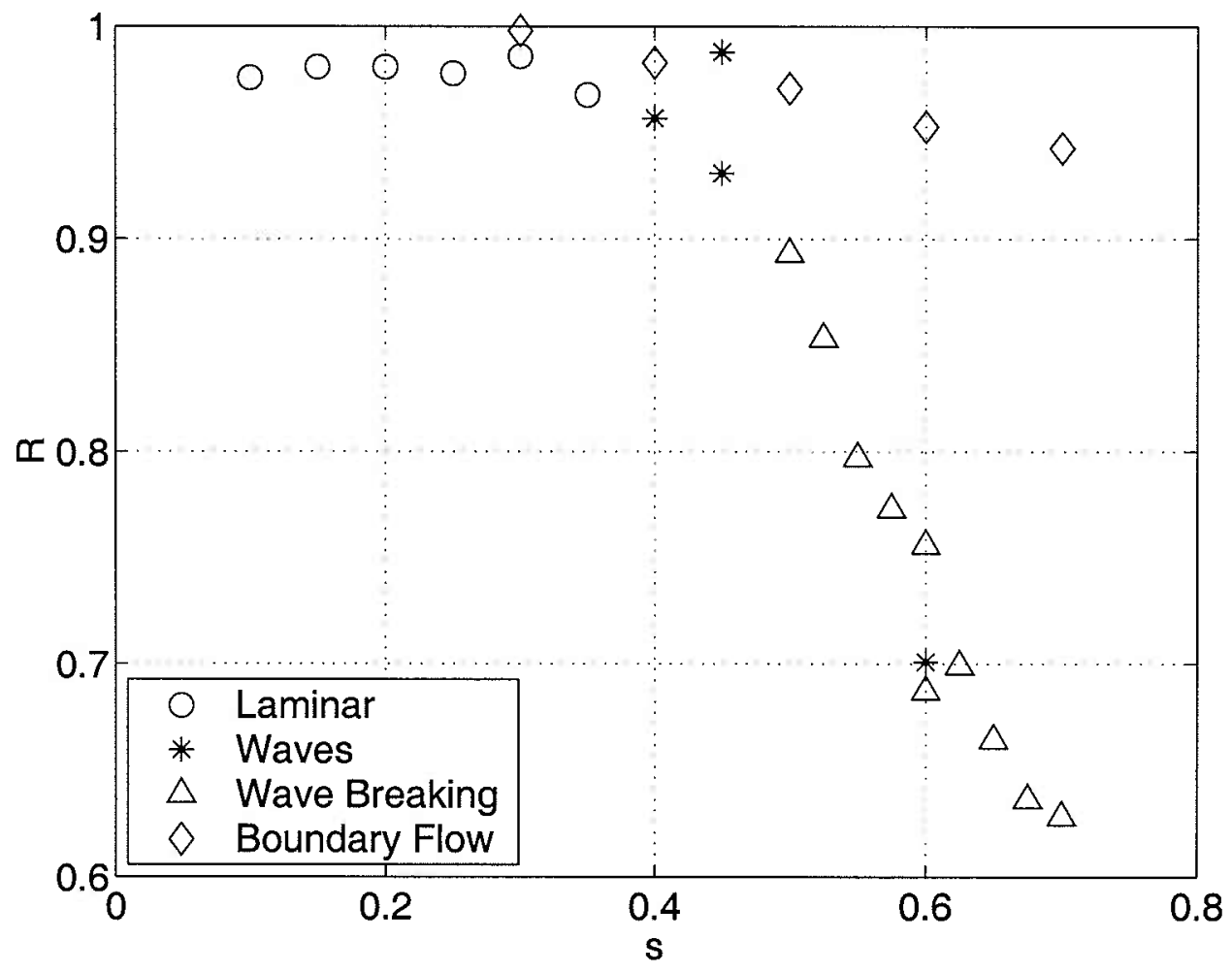

Figure 4-2: The ratio of source water $(R)$ plotted against the slope $(s)$ for experiments with settings $f=1.0 \mathrm{sec}^{-1}, \mathrm{~g}^{\prime}=4 \mathrm{~cm} \cdot \mathrm{sec}^{-2}$, and $Q=2.5 \mathrm{~cm}^{3} \cdot \mathrm{sec}^{-1}$. The flow was in the laminar regime (o) or the wave regime (*) depending on $s$, and the waves were breaking when $s$ was over $0.5(\triangle)$. The results from the experiments done with clockwise rotation for the flow along the boundary $(\diamond)$ show that most of the mixing takes place on the sloping bottom. Lower $\mathrm{R}$ indicates more mixing on the sloping bottom. 


\subsubsection{Rotation and Mixing}

As noted in the introduction of this thesis, overflow takes place at different latitudes and the Coriolis parameter changes by four-fold between the regions of Denmark Strait overflow and the Red Sea overflow. Experiments were done under the same conditions described in the previous subsection, but with the rotation rate set to $f=0.25 \mathrm{sec}^{-1}$. Figure 4-3 shows that there was less mixing for the experiments done with $f=0.25 \mathrm{sec}^{-1}$ and the transition of the flow from the laminar regime to the wave regime took place at a lower $s$. The flow did not reach the western boundary before it reached the end of the sloping bottom, and the difference in $R$ between the results from the experiments with $f=1.0 \mathrm{sec}^{-1}$ can not be fully accounted for by the mixing due to the flow along the boundary. This result shows that lower $f$ was the reason for higher $R$.

More experiments were done to study the difference in mixing depending on the rotation rate ( $f$ ) by changing $f$ from 0 to $2.0 \mathrm{sec}^{-1}$ at $0.5 \mathrm{sec}^{-1}$ increment while setting the other parameters constant at $\mathrm{s}=0.6, \mathrm{~g}^{\prime}=4 \mathrm{~cm} \cdot \mathrm{sec}^{-2}$, and $\mathrm{Q}=2.5 \mathrm{~cm}^{3} \cdot \mathrm{sec}^{-1}$. Figure 4-4 shows that $R$ ranged between 0.69 and 0.99 , having a minimum near $f=1.0$ $\mathrm{sec}^{-1}$. The mixing increased as $f$ was increased from 0 to $1.0 \mathrm{sec}^{-1}$, and decreased as $f$ was further increased from 1.0 to $2.0 \mathrm{sec}^{-1}$. The flow was in the laminar regime when $f=2.0 \mathrm{sec}^{-1}$ and was in the wave regime for all other rotating rates. The waves and the breaking of the waves on the sloping bottom became more vigorous as $f$ was increased from 0 to $1.0 \mathrm{sec}^{-1}$ (Figures $4-5 \mathrm{a}$ and $\mathrm{b}$ ), and the waves became less vigorous as $f$ was increased from 1.0 to $2.0 \mathrm{sec}^{-1}$, the flow spreading out (Figure $4-5 \mathrm{c}$ ) and the flow becoming laminar at $f=2.0 \mathrm{sec}^{-1}$.

\subsubsection{Flow Rate of Source Water and Mixing}

The dependence of mixing on the flow rate of the source water $(\mathrm{Q})$ was studied to show whether the amount of mixing was affected by the configuration of the source. The second kind of the source (Source B, Figure 3-2) was used for this set of experiments. 


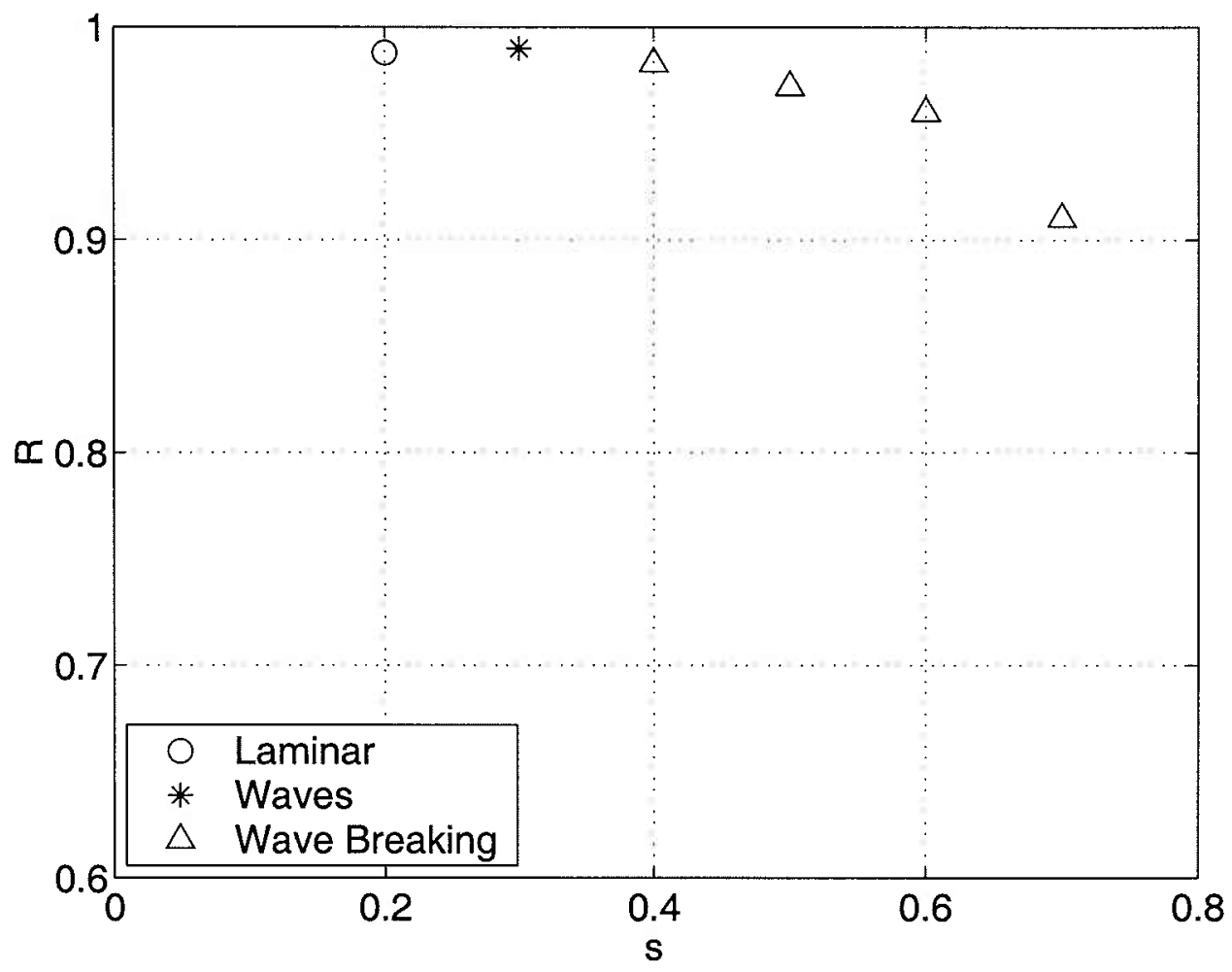

Figure 4-3: The ratio of source water $(R)$ plotted against the slope (s) for experiments with the settings $f=0.25 \mathrm{sec}^{-1}, g^{\prime}=4 \mathrm{~cm} \cdot \mathrm{sec}^{-2}$, and $Q=2.5 \mathrm{~cm}^{3} \cdot \mathrm{sec}^{-1}$. The flow was in the laminar regime (o) or the wave regime (*), and the waves were breaking $(\triangle)$ at higher $\mathrm{s}$. There was less mixing and the flow shifted to the wave regime at a smaller slope compared to the experiments done with $f=1.0 \mathrm{sec}^{-1}$ (Figure 4-2). 


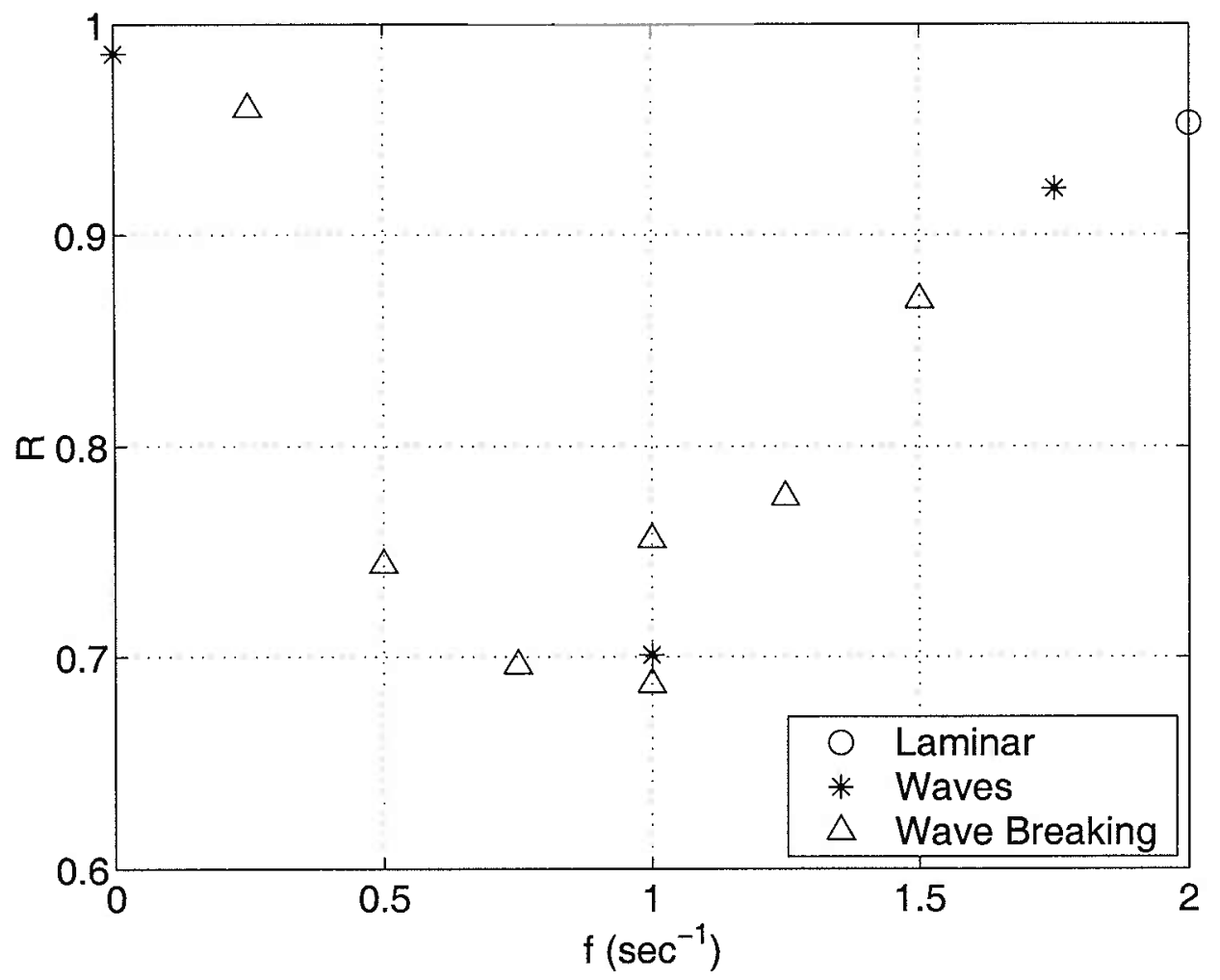

Figure 4-4: The ratio of source water $(R)$ plotted against the rotation rate $(f)$ for experiments with the settings $s=0.6, \mathrm{~g}^{\prime}=4 \mathrm{~cm} \cdot \mathrm{sec}^{-2}$, and $\mathrm{Q}=2.5 \mathrm{~cm}^{3} \cdot \mathrm{sec}^{-1}$. The flow was in the laminar regime (o) when $f=2.0 \mathrm{sec}^{-1}$ and in the wave regime (*) for all other rotation rates, and the waves were breaking $(\triangle)$ for $f$ near $1.0 \mathrm{sec}^{-1}$. 

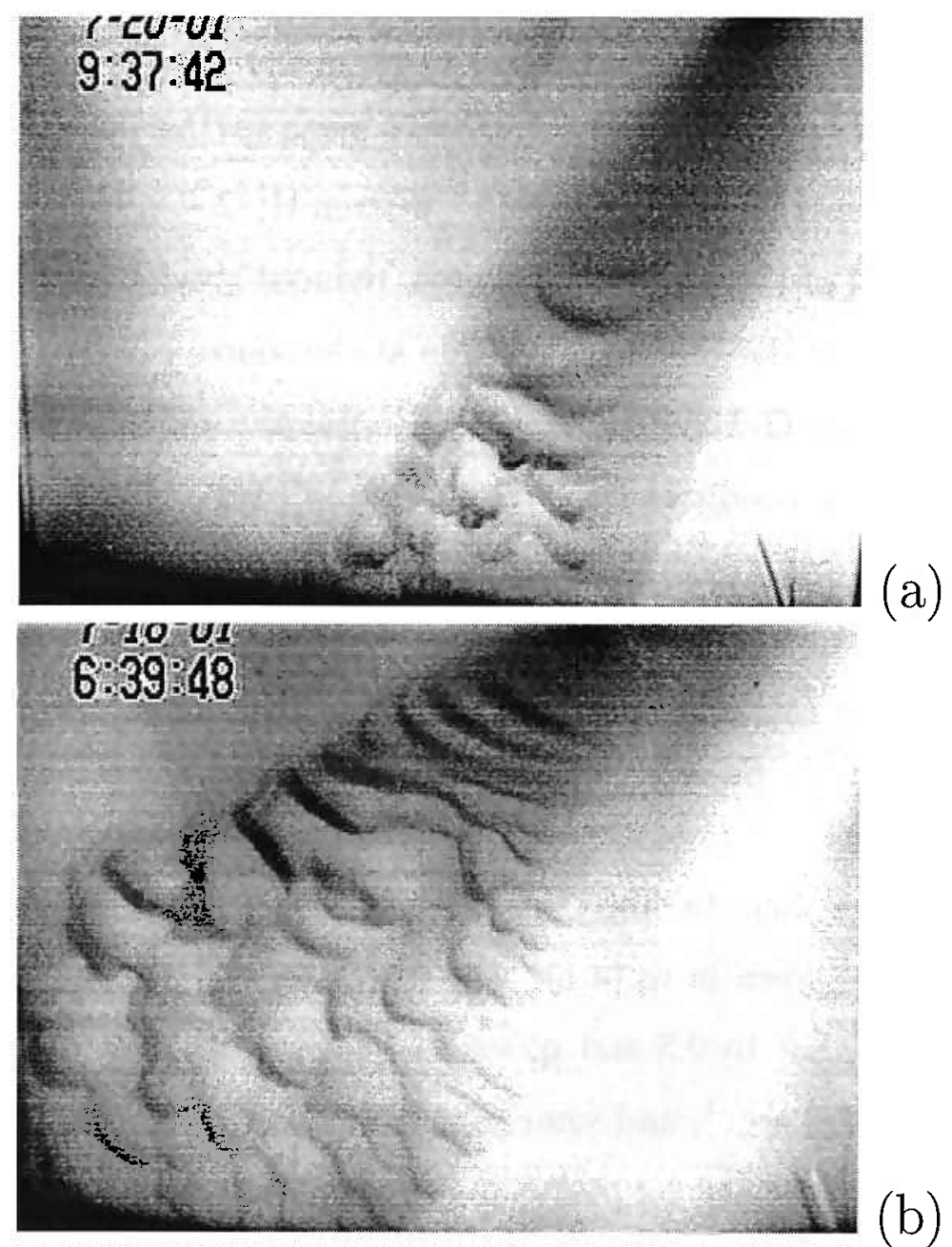

(b)

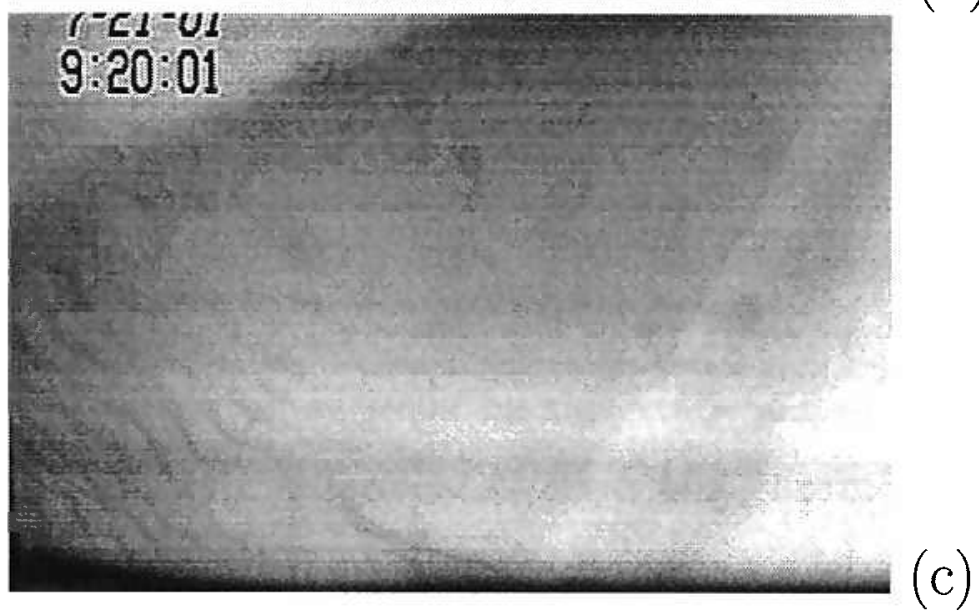

Figure 4-5: Photographs of the flow of the dense water for (a) $f=0.25 \mathrm{sec}^{-1}$, (b) $f=1.0 \mathrm{sec}^{-1}$, and (c) $f=1.75 \mathrm{sec}^{-1}$. The waves became more vigorous as $f$ was increased to $1.0 \mathrm{sec}^{-1}$ and became less vigorous as $f$ was further increased. The waves are faintly observed in the bottom-left corner in (c). 
Various flow rates below the upper limit could be used with this source, and this limit was determined by considering the balance between the inertia and potential energy of the dense water at the source. The condition given is that the momentum energy be lower than the available potential energy, written $\mathrm{U}_{s}^{2} / 2 \leq \mathrm{g}^{\prime} \mathrm{H}_{s}$, where $\mathrm{U}_{\mathrm{s}}, \mathrm{g}^{\prime}$, and $\mathrm{H}_{s}$ denote the speed of the flow at the source, reduced gravity, and the thickness of the dense fluid layer at the source. A relation at the source can be written using the flow rate $(\mathrm{Q})$ as $\mathrm{U}_{\mathrm{s}}=\mathrm{Q} / \mathrm{H}_{\mathrm{s}} \mathrm{W}_{\mathrm{s}}$, where $\mathrm{W}_{\mathrm{s}}$ denotes the width of the source. From these two relations the condition for $Q$ was $Q^{2} \leq 2 g^{\prime} H_{s}^{3} W_{s}^{2}$. The source had a $W_{s}$ of $6 \mathrm{~cm}$ and $H_{s}$ was observed from the side of the tank to be 0.3 to $1.0 \mathrm{~cm}$. The relation the flow rate had to satisfy for the source was

$$
\mathrm{Q}<6 \sqrt{2 g^{\prime}}
$$

Experiments were done to study the relation between the flow rate and mixing under the condition shown in eq.(4.1). The flow rate was changed between 1.1 and $9.2 \mathrm{~cm}^{3} \cdot \mathrm{sec}^{-1}$ with $\mathrm{s}$ set to 0.5 and $\mathrm{g}^{\prime}$ set to $4 \mathrm{~cm} \cdot \mathrm{sec}^{-2}$. Most of the experiments were done with $f=1.0 \mathrm{sec}^{-1}$, and some were were done with $f=0.25 \mathrm{sec}^{-1}$.

Figure 4-6 shows that the ratio of source water (R) increased as $Q$ was increased up to $6 \mathrm{~cm}^{3} \cdot \mathrm{sec}^{-1}$ and then started to decrease as $\mathrm{Q}$ was further increased up to 9 $\mathrm{cm}^{3} \cdot \mathrm{sec}^{-1}$. When $Q$ was less than $1.75 \mathrm{~cm}^{3} \cdot \mathrm{sec}^{-1}$ the source tubing could not be replenished by the source water for over one minute, and during that time the source water was mixing with the fresh water in the source tubing before it reached the slope. The source tubing could not be free of ambient water because the source water in the tubing before beginning the spin-up would be replaced by the ambient water due to the effect of gravity and it would be inevitable to disturb the tank if the source tubing was to be made free of the intrusion of the ambient water. When $Q$ was increased above $7.5 \mathrm{~cm}^{3} \cdot \mathrm{sec}^{-1}$ the dense water flowed out from the source in a turbulent manner. These are likely to be the reasons for the maximum of $R$ near $\mathrm{Q}=6 \mathrm{~cm}^{3} \cdot \mathrm{sec}^{-1}$ in Figure 4-6. 


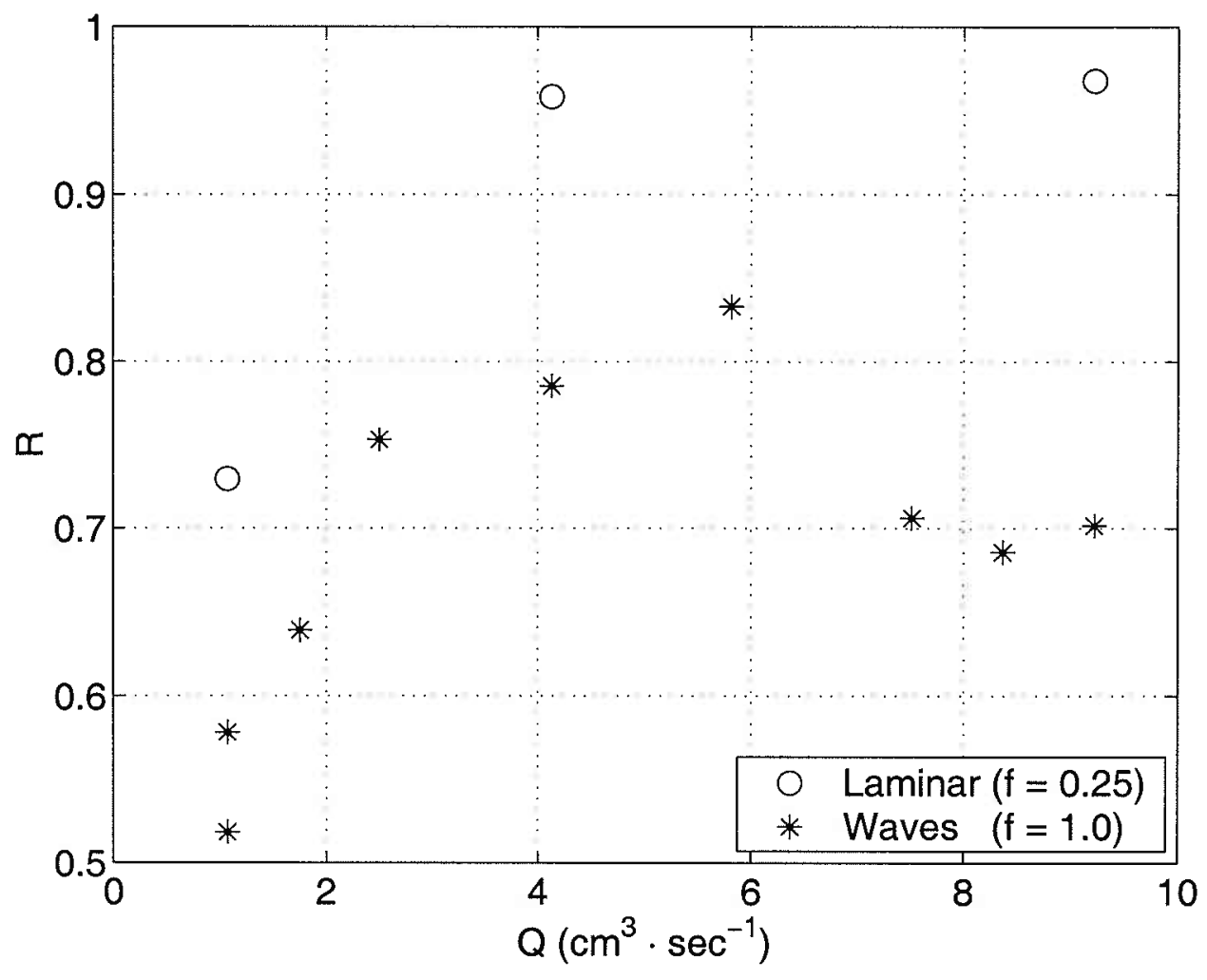

Figure 4-6: The ratio of source water $(R)$ plotted against the flow rate $(Q)$ for experiments with settings $s=0.5$ and $g^{\prime}=4 \mathrm{~cm} \cdot \mathrm{sec}^{-2}$ for $f=0.25$ and $1.0 \mathrm{sec}^{-1}$. The range for $\mathrm{Q}$ was between 1.067 and $9.217 \mathrm{~cm}^{3} \cdot \mathrm{sec}^{-1}$. 


\subsubsection{Froude Number and Mixing}

The relation between the data from the experiments on the one-meter rotating table and the internal Froude number (Fr) was investigated. The internal Froude number was used because it is a relevant governing non-dimensional parameter when considering the effects of the gravitational waves on an interface of fluids (Tritton, 1988). The internal Froude number was defined as $\operatorname{Fr}=U / \sqrt{g^{\prime} H \cos \theta}$, where $U, H$, and $\theta$ denote the speed of the flow on the sloping bottom, thickness of the dense fluid layer, and angle the sloping bottom makes with the bottom of the tank, respectively, and was calculated using the values of $\mathrm{U}, \mathrm{g}^{\prime}$, and $\mathrm{H}$ obtained from the experiments. The speed of the flow was calculated by measuring the $x$ - and $y$-components of the velocity ( $u$ and $v$, respectively) and using $U=\sqrt{u^{2}+v^{2}}$. The velocity components were calculated by tracking the head of the dense fluid flow using the video recordings of the experiments. For most of the experiment on the one-meter rotating table the head of the dense fluid reached the western boundary before arriving at the end of the sloping bottom. In these cases $u$ was obtained by dividing the distance from the source to the western boundary by the time the dense fluid took to reach the western boundary $\left(T_{w}\right)$, and $v$ was obtained by dividing the downslope distance the dense fluid descended by $T_{w}$. For some of the experiments on the one-meter rotating table the dense fluid reached the end of the sloping bottom without coming into contact with the western boundary. In these cases $u$ was obtained by dividing the cross-slope distance the western edge of the dense fluid traveled by the time the fluid took to reach the end of the sloping bottom $\left(\mathrm{T}_{\mathrm{b}}\right)$, and $v$ was obtained by dividing the length of the bottom slope by $T_{b}$. Reduced gravity $\left(g^{\prime}\right)$ was calculated by measuring the density of the ambient water $\left(\rho_{a}\right)$ and source water $\left(\rho_{s}\right)$ and using $g^{\prime}=\left(\rho_{s}-\rho_{a}\right) / \rho_{a}$. The layer thickness of the dense fluid $(\mathrm{H})$ was obtained from

$$
\mathrm{QT}=\mathrm{AH}
$$


where $T$ is $T_{w}$ or $T_{b}$ depending on the flow and $A$ is the area the flow covered on the sloping bottom.

Figure 4-7 shows a decrease of 0.3 in $\mathrm{R}$ near $\mathrm{Fr}=1.5$ and indicates that mixing was sensitive to the values of the internal Froude number. Flows in the laminar regime were observed when Fr was less than 1.6 and flows in the wave regime were observed when Fr was greater than 1.2.

\subsubsection{Ekman Number and Mixing}

The relation between the data from the experiments on the one-meter rotating table and the Ekman number (Ek) was investigated. The Ekman number was used because it is a relevant non-dimensional parameter that measures the effect of rotation and viscosity. The Ekman number is defined as $\mathrm{Ek}=2 \mathrm{v} / \mathrm{fH}^{2}$, where $v, f$, and $\mathrm{H}$ denote the kinematic viscosity, Coriolis parameter, and thickness of the dense layer, respectively, and indicates the ratio of viscous forces to Coriolis forces (Tritton, 1988). The results from the experiments on the one-meter rotating table for the ratio of source water $(R)$ are plotted against Ek in Figure 4-8. Figure 4-8 shows that flows in the laminar regime were observed when the Ekman number was less than 1.8 and flows in the wave regime were observed when Ek was greater than 1.0. For the experiments with waves breaking, $\mathrm{R}$ decreased as Ek increased. With few exceptions, $\mathrm{R}$ had lower values and there was more mixing when Ek was larger.

\subsubsection{Simple Topography and Mixing}

On a research cruise in the Red Sea outflow region in the Gulf of Aden (Red Sea Outflow Experiment (REDSOX) II), the Center Beam Depth (CBD) measured by the ship constantly fluctuated a few meters whether the ship was cruising over a flat bottom or a sloped bottom. Although the fluctuation could be due only to the reading error of the instrument itself, it also could have been reflecting the topographic difference. Suspecting that this difference in topography might be causing more 


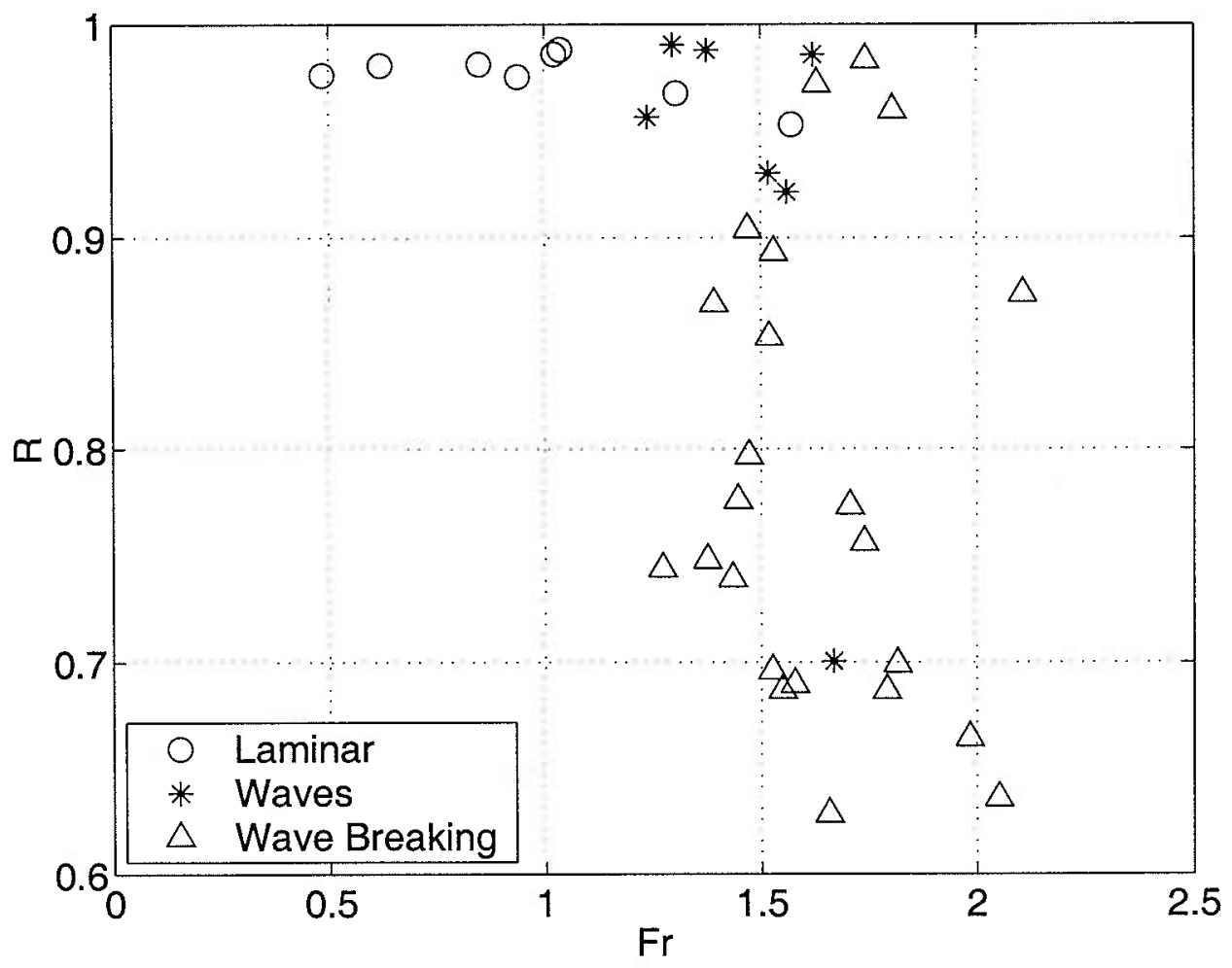

Figure 4-7: The relation between the data from the experiments on the one-meter rotating table and the internal Froude number $\left(\mathrm{Fr}=\mathrm{U} / \sqrt{g^{\prime} \mathrm{H} \cos \theta}\right)$. The ratio of source water $(R)$ is plotted against Fr for the flows in the laminar regime $(0)$, for the flows in the wave regime (*), and for the flows in the wave regime with waves breaking $(\triangle)$. 


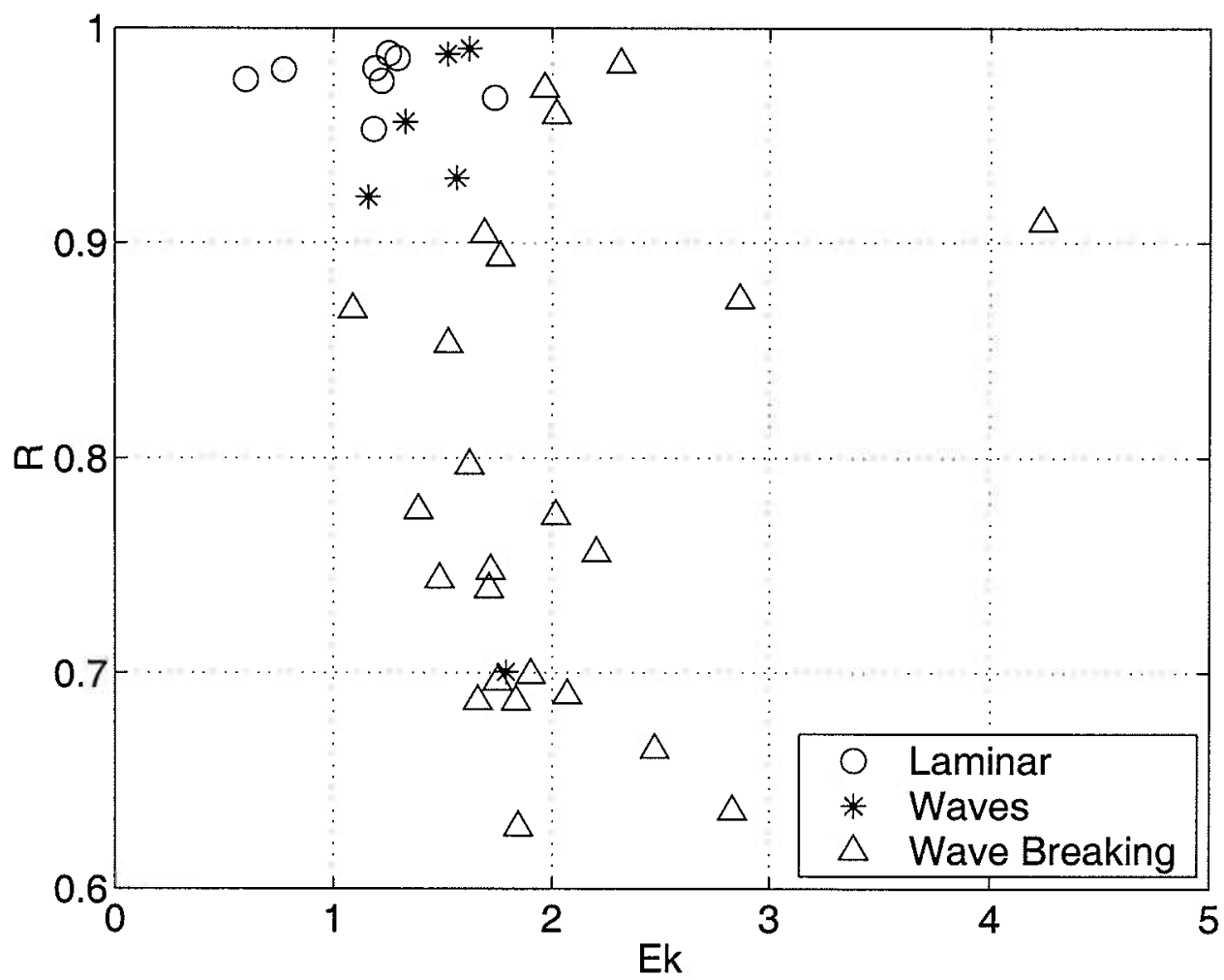

Figure 4-8: The relation between the data from the experiments on the one-meter rotating table and the Ekman number $\left(\mathrm{Ek}=2 \mathrm{v} / \mathrm{fH}^{2}\right)$. The ratio of source water $(\mathrm{R})$ is plotted against Ek for the flows in the laminar regime (o), for the flows in the wave regime (*), and for the flows in the wave regime with waves breaking $(\triangle)$. 
mixing in the ocean rather than the flow on the slope itself, experiments were done with simple bumps on the sloping bottom in the tank to study the effect of topography on mixing.

The bumps were made by placing metal tubes with a diameter of 8 millimeters on the sloping bottom and covering them with duct tape to make a smooth curve that connected the surface of the sloping bottom and the bump. These experiments were done in an attempt to find whether topographic mixing was greater than the mixing caused by the waves observed on the sloping bottom in the experiments. The mixing was compared for cases with 0 to 3 bumps. Figure 4-9 shows that the mixing for all cases were similar to each other. For all cases the bumps acted as reservoirs and reduced the speed of the flow, and the flow was subcritical over the bumps. 


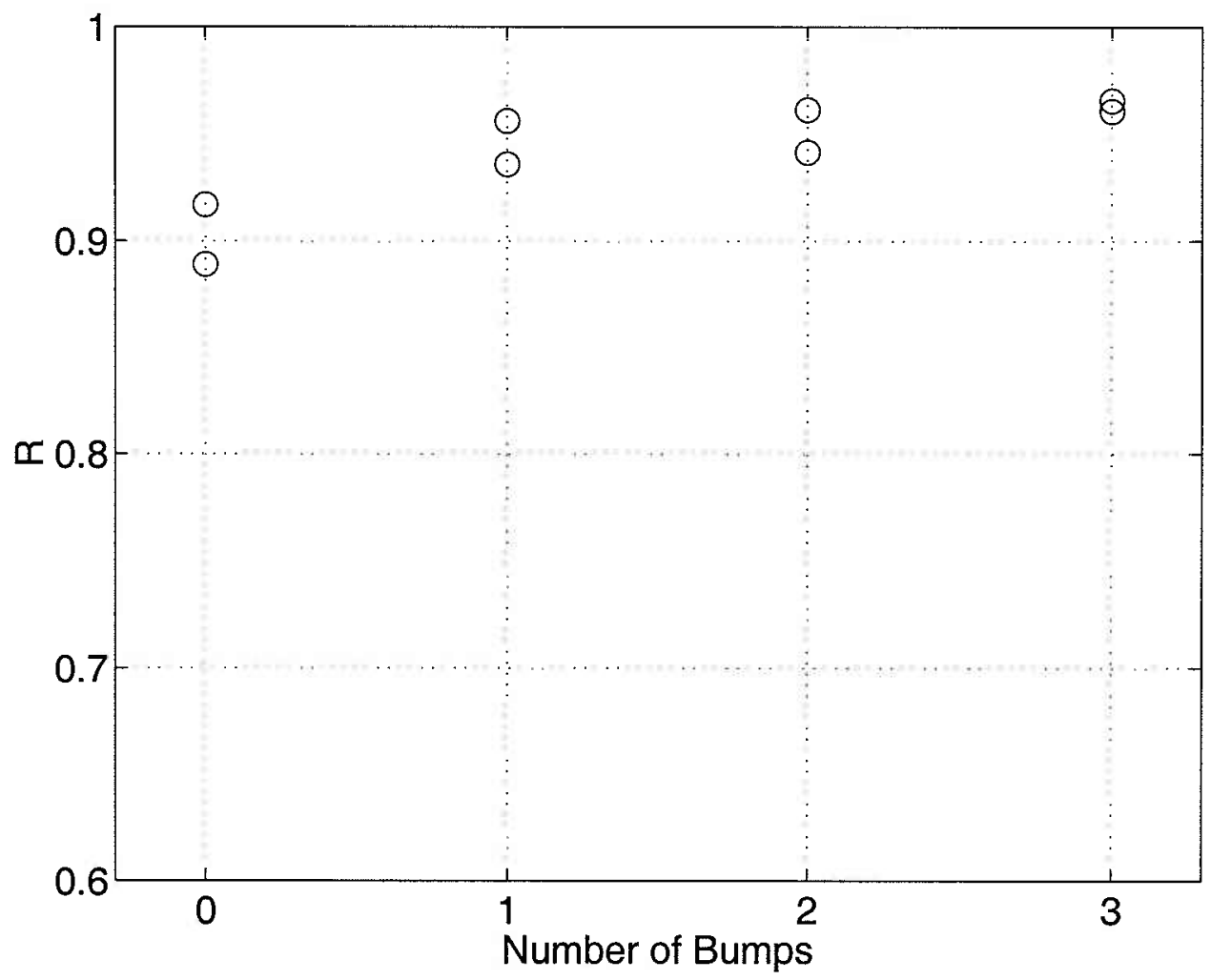

Figure 4-9: The ratio of source water ( $R$ ) plotted against the number of bumps for experiments with the settings $s=0.5, f=1.0 \mathrm{sec}^{-1}, \mathrm{~g}^{\prime}=4 \mathrm{~cm} \cdot \mathrm{sec}^{-2}$, and $\mathrm{Q}=2.5$ $\mathrm{cm}^{3} \cdot \mathrm{sec}^{-1}$. The number of bumps did not affect the amount of mixing. 


\subsection{Results From the Experiments on the Two- meter Rotating Table}

\subsubsection{Flow Characteristics}

The results from the experiments on the two-meter rotating table are described in this section. The advantage of using a larger table and a tank was to be able to have a sloping bottom with a greater length and allowing the dense flow longer time to develop waves. While the slope (s) was set to 0.2 for the experiments, the rotation rate (f) was changed between 0.25 and $1.5 \mathrm{sec}^{-1}$, the reduced gravity $\left(\mathrm{g}^{\prime}\right)$ was changed between 1 and $35 \mathrm{~cm} \cdot \mathrm{sec}^{-2}$, and the flow rate (Q) was changed between 2.77 and 12.2 $\mathrm{cm}^{3} \cdot \mathrm{sec}^{-1}$. The sloping bottom stretched across the entire width of the tank, $2 \mathrm{~m}$ at the widest point and $1.6 \mathrm{~m}$ at the narrowest point, and was wide enough that the density current did not touch the side boundary as it descended the sloping bottom for all the values for $f$ used in the experiments. The second source (Source B) described in Section 3.1 was used for the experiments on the two-meter rotating table.

Depending on the parameter setting, the head of the dense fluid took 63 to 405 seconds to reach the end of the sloping bottom, and the western edge of the head of the fluid reached 30 to $160 \mathrm{~cm}$ away from the source in the cross-slope direction. Bottom water samples revealed that the source water ratio $(R)$ ranged between 0.62 and 0.99. The flow was in the laminar regime when $f$ was high and $g^{\prime}$ was low, and in the wave regime when $f$ was small and $g^{\prime}$ was high. The waves were observed to break when $Q$ was increased. Some combinations of low $g^{\prime}$ and high $f$ caused the fluid to form eddies (eddy regime) and not a gravity current that stayed on and descended the sloping bottom. The mixing in the eddy regime was not studied because the dense fluid did not reach the end of the slope and there was no bottom water to be collected when the flow was in the eddy regime. 


\subsubsection{Non-dimensional Numbers and Mixing}

The results from the experiments are studied using non-dimensional parameters. First, the relation between the results from the experiments and the internal Froude number was studied. The internal Froude number (Fr) and reduced gravity $\left(\mathrm{g}^{\prime}\right)$ are defined and calculated as described in Subsection 4.2.5. For the experiments on the two-meter rotating table only the time it took the dense fluid to reach the end of the bottom slope $\left(T_{b}\right)$ was used the for the calculation of Fr because the dense fluid did not touch the western boundary. The layer thickness of the dense fluid $(\mathrm{H})$ was obtained from

$$
\mathrm{QT}_{\mathrm{b}}=\mathrm{AH},
$$

where $A$ is the area covered by the dense fluid on the sloping bottom. The area of the flow was calculated by approximating the area the flow covered as a trapezoid, where the upper-base was taken as the width of the source $(6 \mathrm{~cm})$, the lower-base was taken as the width of the flow at the end of the sloping bottom, and the height was taken as the length of the bottom slope. The formula given as eq.(4.3) does not take into account the difference in layer thickness due to waves, but provides an estimate of the layer thickness which could not be obtained directly because the flow could not be observed from the sides.

Figure 4-10 shows that the flow was in the laminar regime when Fr was between 0.3 and 1.0, and was in the wave regime when Fr was higher and between 0.4 and 1.4. The waves were breaking when Fr was over 0.8. The data points from the laminar flow (o) take lower Fr and $R$ values and occupy the bottom-left corner of the figure, and the data points from the flow with the waves breaking $(\Delta)$ take higher Fr and $R$ values and occupy the upper-right corner of the figure, while the data points from the flow in the wave regime (*) fill in the gap in between.

The pattern that the data points from the experiments on the two-meter rotating table made on the Fr-R plot (Figure 4-10) is different from that made based on the 


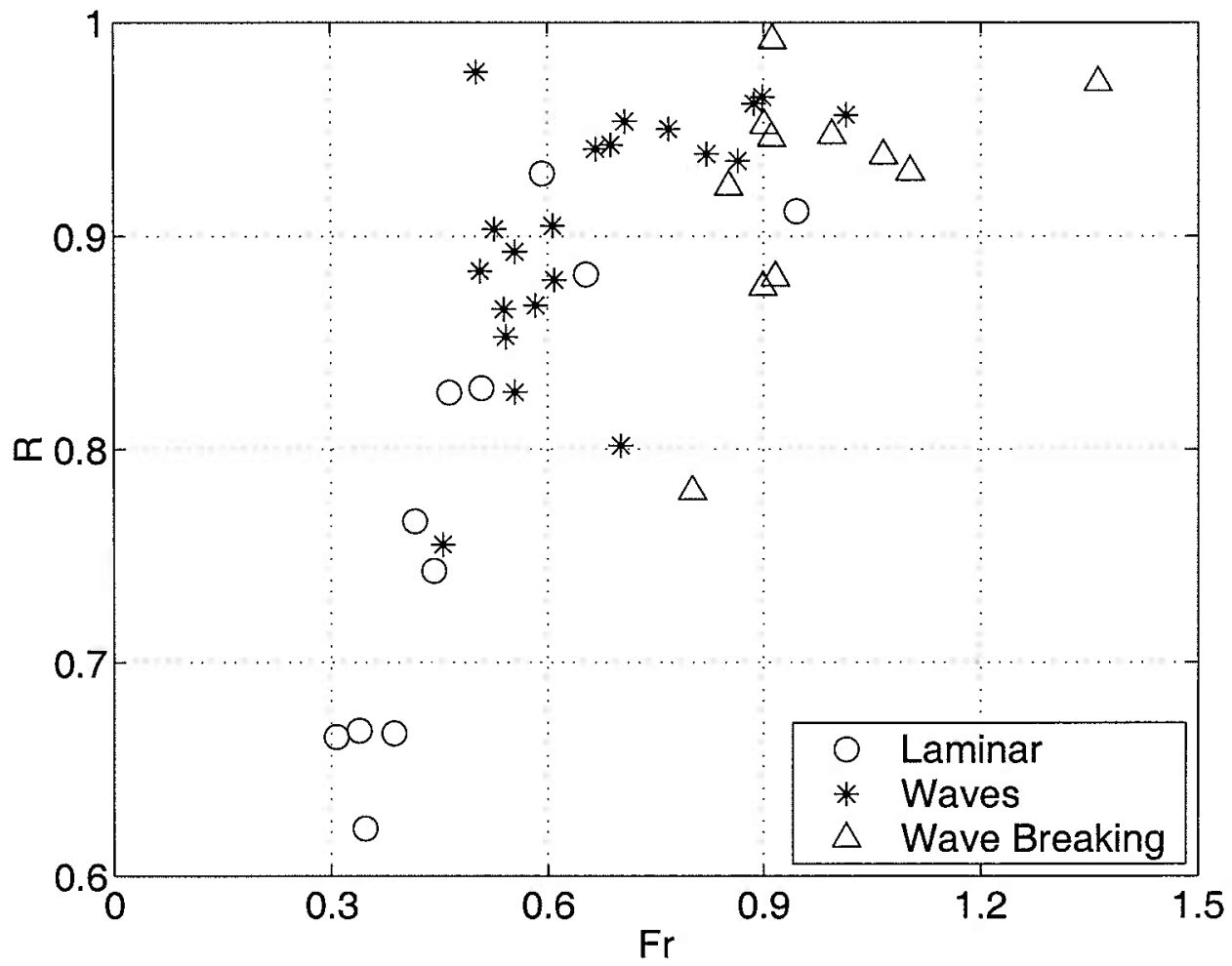

Figure 4-10: The data from the experiments on the two-meter rotating table plotted against the internal Froude number $\left(\mathrm{Fr}=\mathrm{U} / \sqrt{\mathrm{g}^{\prime} \mathrm{H} \cos \theta}\right)$. The ratio of source water (R) is plotted against Fr for the flows in the laminar regime (o), for the flows in the wave regime (*), and for the flows in the wave regime with waves breaking $(\triangle)$. 
data points from the experiments on the one-meter rotating table (Figure 4-7). This difference in the pattern of the Fr-R plots will be discussed in Section 5.2. The flow in the laminar regime had less mixing (higher R) for the experiments on the one-meter table with a shorter bottom slope, but had more mixing (lower R) on the two-meter table with a longer bottom slope. The flow in the wave regime had more mixing with a shorter bottom slope, but had less mixing with a longer bottom slope.

Second, the relation between the results from the experiments and the Ekman number was studied to reveal a relation between the results and a non-dimensional parameter that includes the effect of rotation. The Ekman number is defined as in Subsection 4.2.6. The thickness of the dense layer was used here because it was the dominant characteristic scale length in the experiments studying the gravity currents on a slope. Figure 4-11 shows the ratio of source water $(R)$ plotted against the Ekman number. Figure 4-11 shows that the flows in the laminar regime was observed when Ek was less than 0.7 and flows in the wave regime were observed when Ek was greater than 0.1. There was less mixing (greater R) when the waves were breaking for a flow in the wave regime at Ek values greater than 0.8 .

Although rotation is not a non-dimensional parameter, the relation between $R$ and $f$ is described here since a connection between the flow regime and mixing was also found when $R$ was plotted against $f$ (Figure 4-12). Figure 4-12 shows the data from the experiments with $\mathrm{Q}=2.77 \mathrm{~cm}^{3} \cdot \mathrm{sec}^{-1}$ and combinations of $\mathrm{f}$ and four different values of $g^{\prime}$. The data points that are connected with solid lines between $f=0.5$ and $1.0 \mathrm{sec}^{-1}$ are for experiments done with $\mathrm{g}^{\prime}=10,15$, and $25 \mathrm{~cm} \cdot \mathrm{sec}^{-2}$, and those connected with a dotted line are for $\mathrm{g}^{\prime}=35 \mathrm{~cm} \cdot \mathrm{sec}^{-2}$. The solid lines show a greater decrease in $\mathrm{R}$ than the dotted line does. The flow regime for the data points connected by the solid lines changed from waves to laminar as $f$ changed from 0.5 to $1.0 \mathrm{sec}^{-1}$, while those connected by the dotted line remained in the wave regime. Experiments with larger $f$ were not studied because the flow shifted to the eddy regime. 


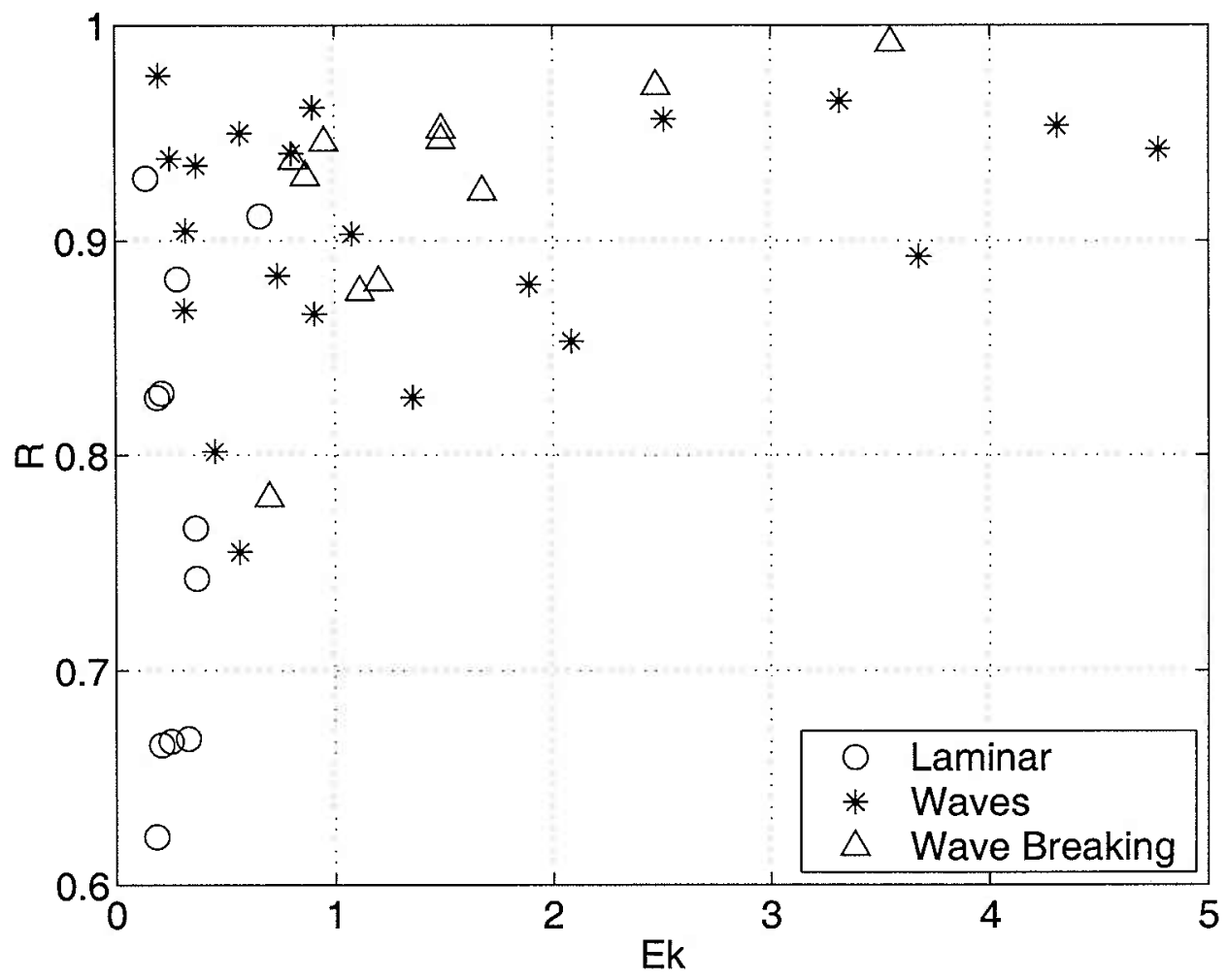

Figure 4-11: The data from the experiments on the two-meter rotating table plotted against the Ekman number $\left(\mathrm{Ek}=2 v / \mathrm{fH}^{2}\right)$. The ratio of source water $(\mathrm{R})$ is plotted against Ek for the flows in the laminar regime (o), for the flows in the wave regime $(*)$, and for the flows in the wave regime with waves breaking $(\triangle)$. 


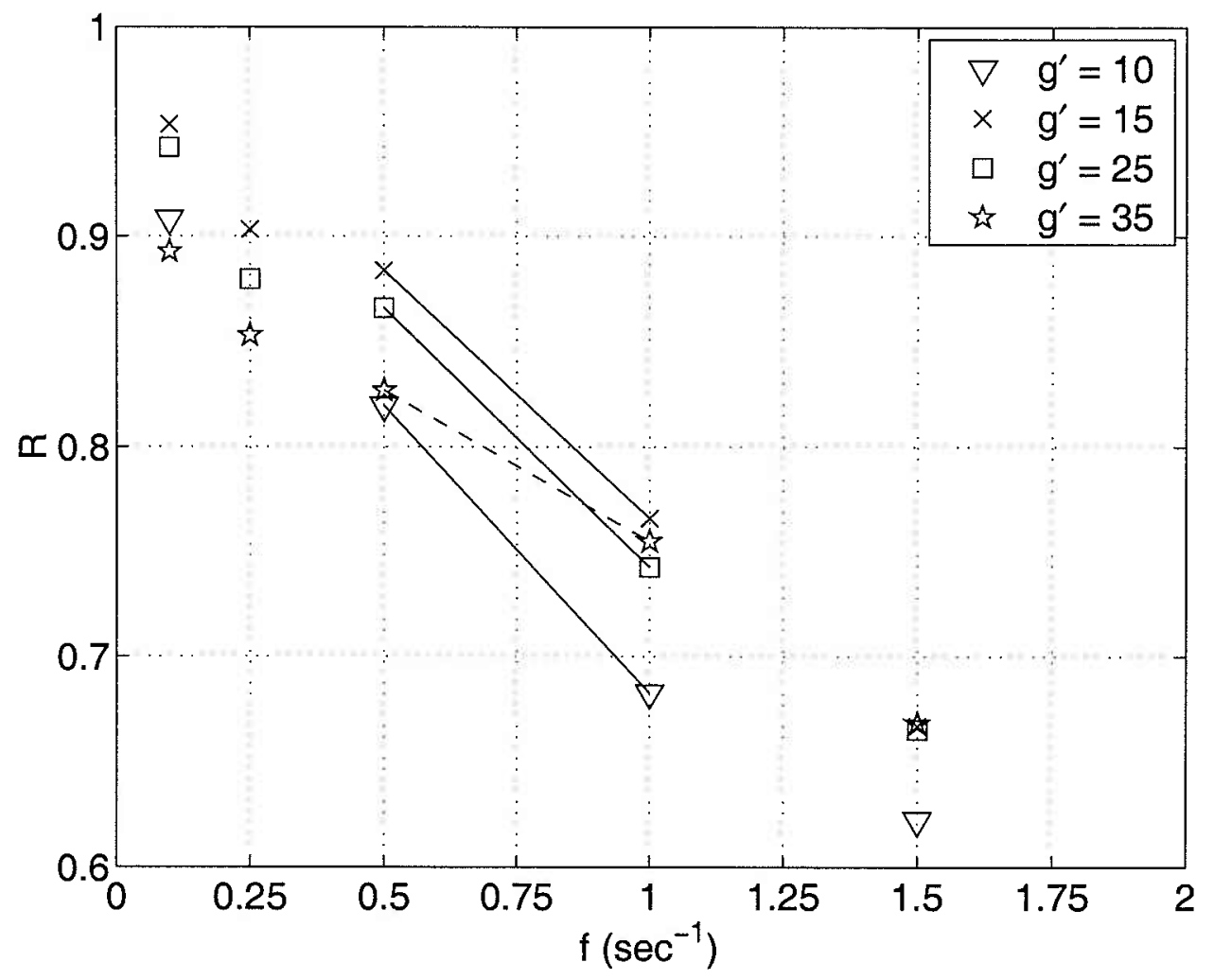

Figure 4-12: The ratio of source water in the bottom water $(R)$ plotted against the rotation rate $(f)$ for experiments with $Q=2.77 \mathrm{~cm}^{3} \cdot \mathrm{sec}^{-1}$ and $\mathrm{g}^{\prime}=10(0), 15(x)$, $25(\square)$, and $35(\star) \mathrm{cm} \cdot \mathrm{sec}^{-2}$. The solid lines connect the data points that the flow regime shifted from waves to laminar as $f$ increased from 0.5 to 1.0. The dotted line connects the data points that the flow regime remained in the wave regime. 


\subsubsection{Diffusion and Mixing}

An increase in $R$ with $F r$ and the decrease in $R$ as the flow shifted from the laminar regime to the wave regime suggest that a mechanism other than mechanical mixing might be involved in what determines $R$ at the end of the sloping bottom. Diffusion was considered given that there was increased mixing when the flow was laminar and the flow took longer to descend the sloping bottom.

The diffusion equation is written as

$$
\frac{\partial C}{\partial t}=D \nabla^{2} C
$$

where $\mathrm{C}$ and $\mathrm{D}$ denote the concentration and diffusivity, respectively. Assuming that the concentration is uniform in the horizontal direction and replacing $\nabla^{2}$ with $\partial^{2} / \partial z^{2}$,

$$
\frac{\partial C}{\partial t}=D \frac{\partial^{2} C}{\partial z^{2}}
$$

Then, the diffusive time scale $\left(T_{d}\right)$ is given by

$$
\mathrm{T}_{\mathrm{d}}=\frac{\mathrm{H}^{2}}{\mathrm{D}}
$$

where $\mathrm{H}$ is the thickness of the dense fluid layer. Figure 4-13 shows the result for this calculation using the diffusion coefficient for salt $\mathrm{D}=1.5 \times 10^{-5} \mathrm{~cm}^{2} \cdot \mathrm{sec}^{-1}$ (Weast, 1984) and $R$ was plotted against the ratio of $T_{b}$ to $T_{d}$. The ratio of source water (R) was higher when $T_{b} / T_{d}$ was smaller, and $R$ linearly decreased as $T_{b} / T_{d}$ increased. Figure 4-13 shows that mixing increased as the time the dense fluid took to reach the bottom became greater compared to the diffusive time scale.

\subsubsection{Ekman Layer in the Flow}

The solution to the two-layer problem described in Chapter 2 shows that the two-layer system has a velocity profile that draws an Ekman spiral. A grain of dye (potassium 


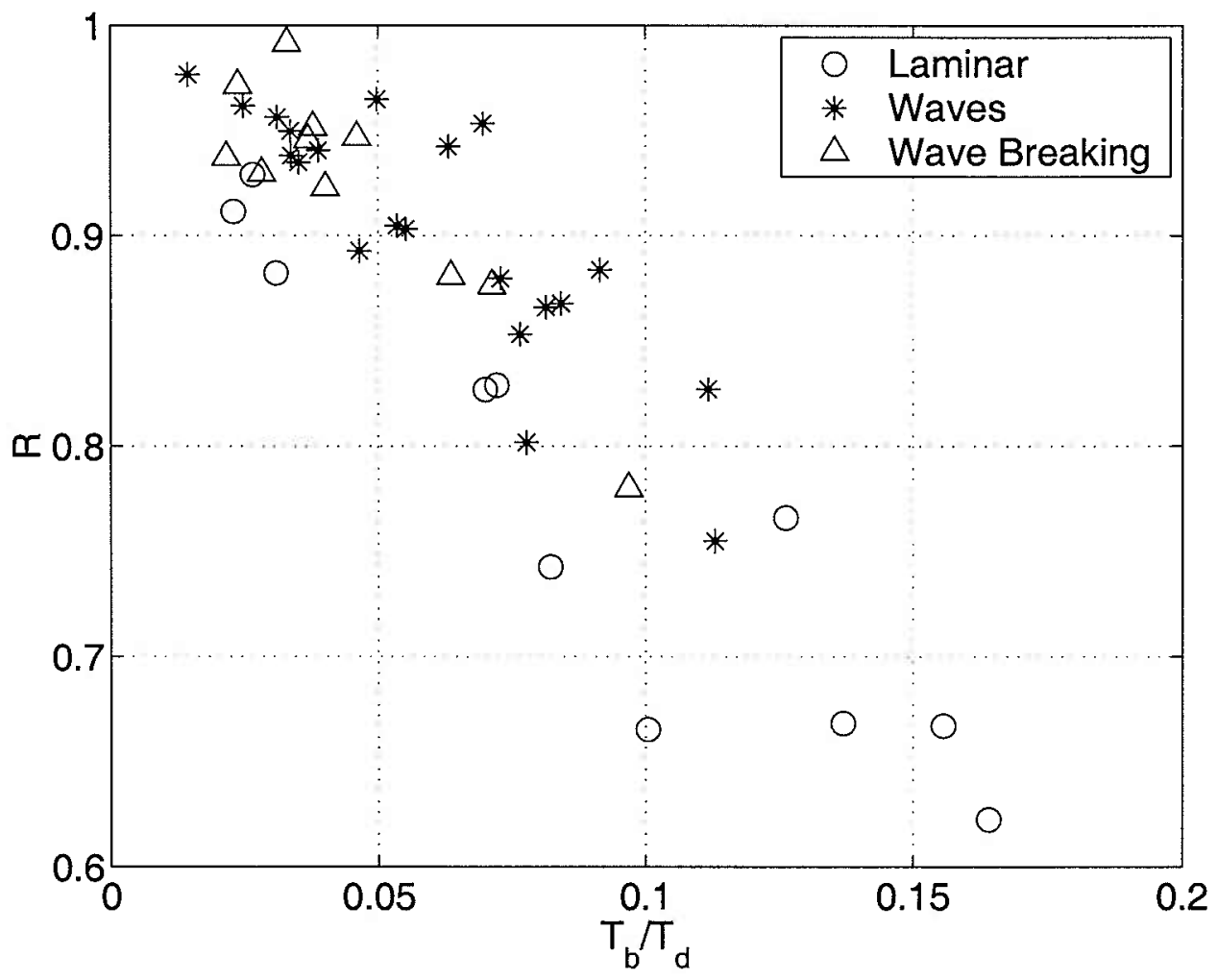

Figure 4-13: The ratio of source water in the bottom water $(R)$ plotted against the ratio of the time the fluid took to reach the bottom $\left(T_{b}\right)$ to the diffusive time scale $\left(T_{d}\right)$. The diffusive time scale was obtained from eq.(4.6) using $\mathrm{D}=1.5 \times 10^{-5} \mathrm{~cm}^{2} \cdot \mathrm{sec}^{-1}$. 
promanganate) was dropped in the tank to observe whether the solution based on an idealized two-layer model reflected the velocity structure in the experiments. Figure 4-14 shows a velocity structure that had a spiral near the surface of the sloping bottom. The spiral at the bottom of the streak in the figure was at the surface of the sloping bottom and extended upward. The spiral had a horizontal scale of about $2 \mathrm{~cm}$ when the picture was taken and continued to spread out to be about $5 \mathrm{~cm}$ in diameter before being dissipated. 


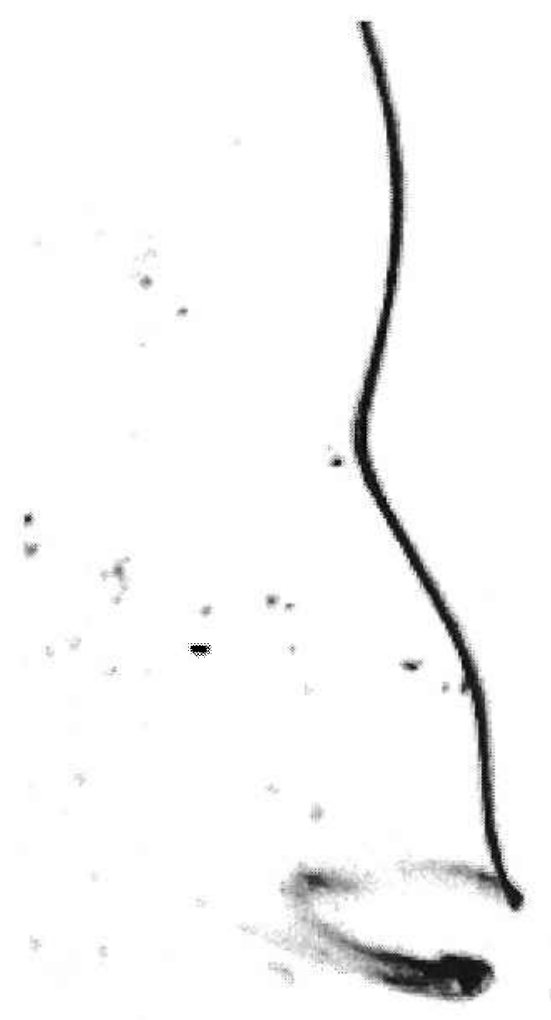

Figure 4-14: An Ekman spiral observed in the flow. A grain of dye (potassium promanganate) was dropped in the tank and the dye left a streak that showed the Ekman spiral near the surface of the sloping bottom. The diameter of the loop at the bottom was about $2 \mathrm{~cm}$. 


\subsection{Experiment Data}

The data from the experiments are shown in the following tables. Tables 4.1 and 4.2 show the results from the experiments on the one-meter and two-meter rotating table, respectively. The tables show the slope $(s)$, rotation rate $\left(f, \sec ^{-1}\right)$, reduced gravity $\left(\mathrm{g}^{\prime}, \mathrm{cm} \cdot \mathrm{sec}^{-1}\right)$, and flow rate $\left(\mathrm{Q}, \mathrm{cm}^{3} \cdot \mathrm{sec}^{-1}\right)$ that was used in the experiments, the ratio of source water $(R)$ calculated from the water samples taken during the experiments, the flow regime, the speed of the head of the gravity current, estimated thickness of the bottom layer $(\mathrm{H}, \mathrm{cm})$, internal Froude number $(\mathrm{Fr})$, and Ekman number (Ek). 
Table 4.1: Results from the experiments on the one-meter rotating table. The columns list the experiment number (EXP), slope $(s)$, rotation $\left(f, \sec ^{-1}\right)$, reduced gravity $\left(g^{\prime}\right.$, $\left.\mathrm{cm} \cdot \mathrm{sec}^{-1}\right)$, flow rate $\left(\mathrm{Q}, \mathrm{cm}^{3} \cdot \mathrm{sec}^{-1}\right)$, ratio of source water $(R)$, flow regime $(1=$ laminar, 2 = waves, 3 = wave breaking), speed of the head (U), thickness of the bottom layer $(\mathrm{H}, \mathrm{cm})$, internal Froude number $(\mathrm{Fr})$, and Ekman number (Ek).

\begin{tabular}{|c|c|c|c|c|c|c|c|c|c|c|}
\hline EXP & $\mathrm{s}$ & $f$ & $g^{\prime}$ & $\mathrm{Q}$ & $\mathrm{R}$ & Regime & U & $\mathrm{H}$ & Fr & Ek \\
\hline 110 & 0.100 & 1.00 & 4.12 & 2.5 & 0.976 & 1 & 0.35 & 0.129 & 0.48 & 1.19 \\
\hline 115 & 0.150 & 1.00 & 4.07 & 2.5 & 0.981 & 1 & 0.42 & 0.114 & 0.62 & 1.53 \\
\hline 116 & 0.200 & 0.25 & 4.16 & 2.5 & 0.988 & 1 & 0.89 & 0.181 & 1.03 & 2.46 \\
\hline 102 & 0.200 & 1.00 & 4.20 & 2.5 & 0.981 & 1 & 0.52 & 0.093 & 0.84 & 2.33 \\
\hline 101 & 0.250 & 1.00 & 4.00 & 2.5 & 0.975 & 1 & 0.56 & 0.092 & 0.92 & 2.37 \\
\hline 119 & 0.300 & 0.25 & 4.09 & 2.5 & 0.990 & 2 & 1.03 & 0.160 & 1.27 & 3.11 \\
\hline 103 & 0.300 & 1.00 & 4.21 & 2.5 & 0.986 & 1 & 0.62 & 0.090 & 1.00 & 2.48 \\
\hline 104 & 0.350 & 1.00 & 4.25 & 2.5 & 0.968 & 1 & 0.73 & 0.078 & 1.27 & 3.28 \\
\hline 117 & 0.400 & 0.25 & 4.10 & 2.5 & 0.983 & 3 & 1.26 & 0.136 & 1.68 & 4.30 \\
\hline 106 & 0.400 & 1.00 & 4.07 & 2.5 & 0.957 & 2 & 0.72 & 0.090 & 1.19 & 2.47 \\
\hline 108 & 0.450 & 1.00 & 4.06 & 2.5 & 0.988 & 2 & 0.77 & 0.085 & 1.31 & 2.78 \\
\hline 114 & 0.450 & 1.00 & 4.08 & 2.5 & 0.930 & 2 & 0.85 & 0.084 & 1.45 & 2.85 \\
\hline 125 & 0.475 & 1.00 & 3.99 & 2.5 & 0.904 & 3 & 0.79 & 0.081 & 1.40 & 3.05 \\
\hline 120 & 0.500 & 0.25 & 3.85 & 2.5 & 0.972 & 3 & 1.17 & 0.151 & 1.54 & 3.52 \\
\hline 105 & 0.500 & 1.00 & 4.13 & 2.5 & 0.893 & 3 & 0.83 & 0.080 & 1.45 & 3.15 \\
\hline 121 & 0.525 & 1.00 & 3.80 & 2.5 & 0.853 & 3 & 0.82 & 0.086 & 1.43 & 2.70 \\
\hline 113 & 0.550 & 1.00 & 4.01 & 2.5 & 0.797 & 3 & 0.80 & 0.084 & 1.38 & 2.84 \\
\hline 123 & 0.575 & 1.00 & 3.94 & 2.5 & 0.773 & 3 & 0.87 & 0.076 & 1.59 & 3.50 \\
\hline 142 & 0.600 & 0.00 & 4.16 & 2.5 & 0.986 & 2 & 1.29 & 0.177 & 1.50 & $\mathrm{~N} / \mathrm{A}$ \\
\hline 143 & 0.600 & 0.25 & 3.88 & 2.5 & 0.873 & 3 & 1.37 & 0.128 & 1.95 & 4.91 \\
\hline 118 & 0.600 & 0.25 & 4.14 & 2.5 & 0.960 & 3 & 1.33 & 0.152 & 1.67 & 3.46 \\
\hline 138 & 0.600 & 0.50 & 3.95 & 2.5 & 0.744 & 3 & 0.83 & 0.125 & 1.18 & 2.55 \\
\hline 132 & 0.600 & 0.50 & 4.10 & 2.5 & 0.739 & 3 & 0.92 & 0.117 & 1.33 & 2.94 \\
\hline 134 & 0.600 & 0.50 & 4.20 & 2.5 & 0.748 & 3 & 0.89 & 0.116 & 1.27 & 2.95 \\
\hline 139 & 0.600 & 0.75 & 4.13 & 2.5 & 0.696 & 3 & 0.88 & 0.094 & 1.41 & 3.00 \\
\hline 133 & 0.600 & 0.75 & 4.14 & 2.5 & 0.690 & 3 & 0.88 & 0.087 & 1.46 & 3.55 \\
\hline 136 & 0.600 & 1.00 & 3.87 & 2.5 & 0.701 & 2 & 0.86 & 0.081 & 1.54 & 3.07 \\
\hline 137 & 0.600 & 1.00 & 3.92 & 2.5 & 0.687 & 3 & 0.93 & 0.080 & 1.66 & 3.15 \\
\hline 107 & 0.600 & 1.00 & 4.10 & 2.5 & 0.756 & 3 & 0.88 & 0.073 & 1.61 & 3.78 \\
\hline 135 & 0.600 & 1.00 & 4.23 & 2.5 & 0.687 & 3 & 0.85 & 0.084 & 1.43 & 2.85 \\
\hline 140 & 0.600 & 1.25 & 4.16 & 2.5 & 0.776 & 3 & 0.78 & 0.082 & 1.34 & 2.38 \\
\hline 141 & 0.600 & 1.50 & 4.11 & 2.5 & 0.869 & 3 & 0.76 & 0.085 & 1.29 & 1.87 \\
\hline 144 & 0.600 & 1.75 & 3.88 & 2.5 & 0.922 & 2 & 0.78 & 0.076 & 1.44 & 1.99 \\
\hline 145 & 0.600 & 2.00 & 3.97 & 2.5 & 0.953 & 1 & 0.77 & 0.070 & 1.45 & 2.03 \\
\hline 122 & 0.625 & 1.00 & 3.82 & 2.5 & 0.699 & 3 & 0.92 & 0.079 & 1.67 & 3.23 \\
\hline 112 & 0.650 & 1.00 & 4.01 & 2.5 & 0.664 & 3 & 0.96 & 0.069 & 1.82 & 4.15 \\
\hline 124 & 0.675 & 1.00 & 3.91 & 2.5 & 0.636 & 3 & 0.94 & 0.065 & 1.87 & 4.69 \\
\hline 126 & 0.700 & 0.25 & 4.12 & 2.5 & 0.910 & 3 & 1.61 & 0.107 & 2.42 & 6.94 \\
\hline 109 & 0.700 & 1.00 & 4.09 & 2.5 & 0.628 & 3 & 0.87 & 0.081 & 1.50 & 3.02 \\
\hline
\end{tabular}


Table 4.2: Results from the experiments on the two-meter rotating table. The columns list the experiment number (EXP), slope $(s)$, rotation $\left(f, \sec ^{-1}\right)$, reduced gravity $\left(\mathrm{g}^{\prime}, \mathrm{cm} \cdot \mathrm{sec}^{-1}\right)$, flow rate $\left(\mathrm{Q}, \mathrm{cm}^{3} \cdot \mathrm{sec}^{-1}\right)$, ratio of source water $(R)$, flow regime $(1=$ laminar, 2 = waves, 3 = wave breaking), speed of the head $(U)$, thickness of the bottom layer $(\mathrm{H}, \mathrm{cm})$, internal Froude number $(\mathrm{Fr})$, and Ekman number (Ek).

\begin{tabular}{|c|c|c|c|c|c|c|c|c|c|c|}
\hline EXP & $s$ & $f$ & $g^{\prime}$ & $\mathrm{Q}$ & $\mathrm{R}$ & Regime & $\mathrm{U}$ & $\mathrm{H}$ & Fr & Ek \\
\hline$\overline{023}$ & $\overline{0.2}$ & 0.10 & 1.1 & 6.07 & $\overline{0.912}$ & 1 & $\overline{0.62}$ & 0.39 & $\overline{0.94}$ & 0.66 \\
\hline 026 & 0.2 & 0.10 & 2.1 & 6.07 & 0.962 & 2 & 0.73 & 0.34 & 0.88 & 0.90 \\
\hline 028 & 0.2 & 0.10 & 10.1 & 9.62 & 0.972 & 3 & 1.93 & 0.20 & 1.35 & 2.45 \\
\hline 039 & 0.2 & 0.10 & 10.1 & 4.35 & 0.965 & 2 & 1.18 & 0.18 & 0.89 & 3.31 \\
\hline 068 & 0.2 & 0.10 & 10.2 & 6.07 & 0.957 & 2 & 1.44 & 0.20 & 1.00 & 2.51 \\
\hline 045 & 0.2 & 0.10 & 15.0 & 2.77 & 0.954 & 2 & 1.06 & 0.15 & 0.70 & 4.31 \\
\hline 053 & 0.2 & 0.10 & 24.3 & 2.77 & 0.943 & 2 & 1.28 & 0.15 & 0.68 & 4.77 \\
\hline 063 & 0.2 & 0.10 & 24.9 & 6.07 & 0.992 & 3 & 1.86 & 0.17 & 0.90 & 3.55 \\
\hline 057 & 0.2 & 0.10 & 35.0 & 2.77 & 0.893 & 2 & 1.33 & 0.17 & 0.55 & 3.67 \\
\hline 027 & 0.2 & 0.25 & 2.1 & 6.07 & 0.882 & 1 & 0.58 & 0.38 & 0.65 & 0.28 \\
\hline 025 & 0.2 & 0.25 & 5.1 & 9.62 & 0.977 & 2 & 0.75 & 0.45 & 0.50 & 0.20 \\
\hline 024 & 0.2 & 0.25 & 5.1 & 6.07 & 0.950 & 2 & 0.89 & 0.27 & 0.76 & 0.57 \\
\hline 040 & 0.2 & 0.25 & 10.0 & 6.07 & 0.946 & 3 & 1.30 & 0.21 & 0.90 & 0.95 \\
\hline 030 & 0.2 & 0.25 & 10.1 & 9.62 & 0.930 & 3 & 1.62 & 0.22 & 1.09 & 0.87 \\
\hline 036 & 0.2 & 0.25 & 10.1 & 4.35 & 0.941 & 2 & 1.00 & 0.23 & 0.66 & 0.80 \\
\hline 044 & 0.2 & 0.25 & 14.8 & 2.77 & 0.903 & 2 & 0.88 & 0.19 & 0.52 & 1.08 \\
\hline 034 & 0.2 & 0.25 & 14.9 & 12.15 & 0.938 & 3 & 1.93 & 0.22 & 1.06 & 0.81 \\
\hline 033 & 0.2 & 0.25 & 15.0 & 6.07 & 0.947 & 3 & 1.55 & 0.17 & 0.99 & 1.49 \\
\hline 049 & 0.2 & 0.25 & 24.8 & 2.77 & 0.880 & 2 & 1.15 & 0.15 & 0.60 & 1.89 \\
\hline 064 & 0.2 & 0.25 & 25.0 & 6.07 & 0.952 & 3 & 1.82 & 0.17 & 0.89 & 1.49 \\
\hline 061 & 0.2 & 0.25 & 32.3 & 6.07 & 0.923 & 3 & 1.89 & 0.16 & 0.84 & 1.68 \\
\hline 054 & 0.2 & 0.25 & 35.0 & 2.77 & 0.853 & 2 & 1.19 & 0.14 & 0.54 & 2.08 \\
\hline 031 & 0.2 & 0.50 & 10.1 & 9.62 & 0.935 & 2 & 1.32 & 0.24 & 0.86 & 0.37 \\
\hline 047 & 0.2 & 0.50 & 15.0 & 2.77 & 0.884 & 2 & 0.79 & 0.17 & 0.50 & 0.74 \\
\hline 050 & 0.2 & 0.50 & 24.7 & 2.77 & 0.866 & 2 & 1.03 & 0.15 & 0.53 & 0.91 \\
\hline 065 & 0.2 & 0.50 & 24.9 & 6.07 & 0.876 & 3 & 1.63 & 0.14 & 0.89 & 1.12 \\
\hline 062 & 0.2 & 0.50 & 31.9 & 6.07 & 0.881 & 3 & 1.85 & 0.13 & 0.91 & 1.20 \\
\hline 055 & 0.2 & 0.50 & 35.1 & 2.77 & 0.827 & 2 & 1.14 & 0.12 & 0.55 & 1.36 \\
\hline 029 & 0.2 & 0.75 & 10.1 & 9.62 & 0.929 & 1 & 1.04 & 0.31 & 0.59 & 0.14 \\
\hline 035 & 0.2 & 0.75 & 14.8 & 12.15 & 0.938 & 2 & 1.51 & 0.23 & 0.81 & 0.25 \\
\hline 032 & 0.2 & 0.75 & 14.9 & 6.07 & 0.905 & 2 & 1.05 & 0.21 & 0.60 & 0.32 \\
\hline 037 & 0.2 & 1.00 & 10.1 & 4.35 & 0.827 & 1 & 0.70 & 0.23 & 0.46 & 0.19 \\
\hline 048 & 0.2 & 1.00 & 15.3 & 2.77 & 0.766 & 1 & 0.66 & 0.17 & 0.41 & 0.36 \\
\hline 051 & 0.2 & 1.00 & 25.1 & 2.77 & 0.743 & 1 & 0.89 & 0.17 & 0.44 & 0.37 \\
\hline 066 & 0.2 & 1.00 & 25.6 & 6.07 & 0.802 & 2 & 1.36 & 0.15 & 0.69 & 0.45 \\
\hline 056 & 0.2 & 1.00 & 35.2 & 2.77 & 0.755 & 2 & 0.98 & 0.13 & 0.45 & 0.57 \\
\hline 059 & 0.2 & 1.00 & 36.1 & 6.07 & 0.780 & 3 & 1.65 & 0.12 & 0.79 & 0.70 \\
\hline 038 & 0.2 & 1.50 & 10.1 & 2.77 & 0.622 & 1 & 0.48 & 0.19 & 0.34 & 0.18 \\
\hline 046 & 0.2 & 1.50 & 15.2 & 2.77 & 0.667 & 1 & 0.61 & 0.16 & 0.38 & 0.25 \\
\hline 052 & 0.2 & 1.50 & 25.1 & 2.77 & 0.665 & 1 & 0.65 & 0.18 & 0.30 & 0.21 \\
\hline 067 & 0.2 & 1.50 & 25.7 & 6.07 & 0.829 & 1 & 1.08 & 0.18 & 0.50 & 0.21 \\
\hline 060 & 0.2 & 1.50 & 35.3 & 6.07 & 0.868 & 2 & 1.32 & 0.15 & 0.58 & 0.32 \\
\hline 058 & 0.2 & 1.50 & 35.3 & 2.77 & 0.668 & 1 & 0.76 & 0.14 & 0.34 & 0.33 \\
\hline
\end{tabular}




\section{Chapter 5}

\section{Summary and Discussion}

\subsection{Primary Results}

It was found in the laboratory experiments that the flow regime and the ratio of source water $(\mathrm{R})$, which was used as an indicator for mixing, changed depending on the setting of the slope $(s)$, rotation rate $(f)$, reduced gravity $\left(g^{\prime}\right)$, and flow rate of the source water $(\mathrm{Q})$. The mixing on the sloping bottom was associated with the shift between the laminar regime and the wave regime through experiments where the angle of the slope and the rotation rate were changed. As the slope was increased the downslope component of the velocity of the gravity current increased and intensified the waves in the flow. Rotation affected the mixing causing the fluid to spread on the sloping bottom. When the parameter setting for $s, g^{\prime}$, and $Q$ produced vigorous waves the spreading of the fluid due to rotation caused the mixing to increase up to $f=1 \sec ^{-1}$ as the flow covered a larger area with waves.

The results from the experiments were compared to two nondimensional parameters. The first was the internal Froude number (Fr), which measures the effect of gravity waves on an interface of fluids, and the second was the Ekman number (Ek), which measures the effect of viscosity and rotation. The results for $R$ plotted against Fr and Ek showed that there were critical values for the two non-dimensional numbers 
where the regime of the flow changed, and that mixing could be associated with Fr and Ek.

The general pattern of the plots of $R$ against the internal Froude number and Ekman number differ between the results from the experiments on the two different rotating tables. First, the reason for the discrepancy for Fr will be considered. It is reasonable to assume that the flow could have waves breaking when the internal Froude number of the flow is greater than unity because Fr measures the ratio of the speed of the current to that of the internal waves. Matching the point where the flow changed its regime shows that the internal Froude number was slightly larger than expected for the experiments on the one-meter rotating table and that it was about half the expected value for the experiments on the two-meter rotating table. However, because experiments often do not match the theory exactly, the focus of the discussion will be on the discrepancy between the results from the experiments on the two different rotating tables. Referring to the definition of the internal Froude number ( Fr $\left.=\mathrm{U} / \sqrt{g^{\prime} \mathrm{H} \cos \theta}\right)$ shows that Fr could be underestimated by an underestimate of the speed of the gravity current (U) or an overestimate of the thickness of the bottom layer $(H)$. The speed of the gravity current could have been underestimated because the estimate for $\mathrm{U}$ was obtained by dividing the edge of the current and the length of the slope for the $x$-component $(u)$ and the $y$-component $(v)$, respectively, by the time the head of the gravity current reached the end of the bottom slope. It is possible that the head of the gravity current was descending the sloping bottom slower than the trailing fluid for some of the experiments due to the entrainment drag acting on the head. This idea is supported by previous studies showing that the head of the fluid travels slower than the trailing part of the fluid (Middleton, 1966; Britter and Linden, 1980) and by the observation that the head of the dense layer of fluid was taken over by the waves in the trailing fluid for some experiments when waves were breaking. It is not clear whether $\mathrm{H}$ was overestimated or underestimated because $\mathrm{H}$ was derived from eq.(4.3) based on $T_{b}$ and $A$. The time the fluid in the current took 
to reach the end of the sloping bottom might be overestimated for the same reason for an underestimate of $\mathrm{U}$, and the area that the gravity current covered might be overestimated. The overestimate for $A$ is because the waves were not observed over all the area on the sloping bottom that was covered with the fluid, and some fluid covering the sloping bottom was drained by the bottom Ekman layer. Table 4.1 shows that the estimate for $\mathrm{H}$ for the experiments on the one-meter rotating table was often less than a millimeter. The internal Froude number for the experiments on the one-meter table was recalculated using $\mathrm{H}=0.2 \mathrm{~cm}$ regardless of the estimate of $\mathrm{H}$ because it was suspected that the estimate was too low. The recalculation showed that Fr ranged between 0.3 and 1.5, with most data points falling in between 0.9 and 1.2 , showing that low estimate for $\mathrm{H}$ was a major reason for causing the discrepancy for Fr depending on the rotating table. The $\mathrm{H}$ used for the recalculation was the mean value of the estimate for $\mathrm{H}$ for the experiments on the two-meter rotating table.

Second, the plots of $\mathrm{R}$ against the Ekman number $\left(\mathrm{Ek}=2 v / \mathrm{fH}^{2}\right)$ will be discussed. Waves can be expected to appear in the gravity current descending the sloping bottom when $\mathrm{Ek}$ is greater than unity. This is because the Ekman number can be rewritten as $\mathrm{Ek}=\left(\delta_{\mathrm{E}} / \mathrm{H}\right)^{2}$, where $\delta_{\mathrm{E}}$ is the Ekman layer thickness, and Ek $>1$ means that the thickness of the Ekman layer is greater than that of the bottom layer and the Ekman layer cannot be contained within the dense fluid layer. The general pattern the data points made in Figures 4-8 and 4-11 were different due to the difference in $R$ depending on the parameter setting. The few data points being outside of the cluster of data points in Figure 4-8 was due to low $f$ used in the experiments.

The model presented in Chapter 2 had an Ekman layer solution with a vertical velocity profile with a spiral. The vertical velocity profile was successfully visualized by dropping a grain of dye (potassium promanganate) in the laminar part of the flow. The grain of dye left a streak of a spiral near the surface of the sloping bottom showing that the theory adequately described the velocity profile in the gravity current. when a grain of dye was dropped in the flow where there were waves the dye was wrapped 
in the waves and left a circular streak. The circular streak of the dye in the waves could not be photographed despite attempts.

Diffusion was suspected as a possibility to reduce $R$ in the experiments, but the time the experiments took was less than $20 \%$ of the time scale for diffusion. Diffusion is not considered as the main component for mixing for this reason.

The waves in the gravity current on the sloping bottom were observed from 20 $\mathrm{cm}$ away from the side of the tank in the experiments on the one-meter rotating table. The waves were breaking in a manner described as roll waves (see Simpson, 1997). The velocity shear between the layers caused by the descent of the bottom layer created roll-wave like features, and the top of these wave was extracted as a filament from the dense bottom layer. The initial hypothesis was that mixing was associated with the waves in the gravity current, but vigorous waves were not always associated with active mixing. The waves developed more when $g^{\prime}$ was higher and the gravity current had a larger downslope velocity component, but it is speculated that with a higher $\mathrm{g}^{\prime}$ there was greater gravitational restoring force to suppress the dense layer fluid from forming a filament that could be extracted into the ambient fluid.

\subsection{Comparison of Results}

First, the qualitative characteristics of the laboratory experiments will be compared to previous studies. Dickson and Brown (1994) reported the lack of seasonal variability and energetic fluctuation in the Denmark Strait overflow. The laboratory experiments were done with constant flow rate of the dense source water throughout the experiments that corresponds to constant overflow in the ocean. When the flow along the sloping bottom was in the wave regime, the waves observed on the sloping bottom in the rotating tank experiments were on the scale of the mean current depth, matching the description of the large fluctuations observed in the current meter records. 
However, there is the possibility that the fluctuations are due to eddies passing and not due to waves in the overflow current. Baringer and Price (1997a) pointed out in the study of the Mediterranean outflow that active mixing could be taking place on the sloping bottom, especially in the sections where the Froude number was greater than unity. The results from the laboratory experiments on the one-meter rotating table showed that mixing increased as the internal Froude number increased.

The model results presented by Jungclaus and Backhaus (1994) showed the development of the head of the gravity current along a sloping bottom. The plume was $40 \mathrm{~m}$ thick over the largest area covered by the same thickness of dense fluid, and the head of the gravity current had reached about $90 \mathrm{~m}$ thick (Figure 3 of Jungclaus and Backhaus, 1994). The laboratory experiments also showed the development of the head of the current, and the trailing part of the dense layer showed wave amplitude that was comparable to the depth of the dense fluid layer when the flow was in the wave regime. Results from the study of overflow using a three-dimensional numerical model presented by Jiang and Garwood (1995) indicate waves on the gravity current on a sloping bottom (Figure 4). The sloping bottom extended $400 \mathrm{~km}$ in the $x$-direction with the model having the resolution of $4 \mathrm{~km}$, and waves can be seen with about $90 \mathrm{~km}$ between each crest that is about $300 \mathrm{~m}$ high. The waves in the dense fluid layer in the laboratory experiments had crests that were about $2 \mathrm{~cm}$ apart from each other and about $1 \mathrm{~cm}$ high.

This study has shown that the trailing part of a gravity current is also an important component to take into account in addition to the head of the gravity current when considering the mixing of dense overflow water and the ambient fluid.

Next, the quantitative results from the experiments will be compared to previous studies. Often the effect of entrainment is measured by an entrainment parameter $E$ defined as

$$
E=\frac{w_{E}}{U}
$$

where $w_{E}$ is the entrainment velocity and $U$ is the speed of the flow. Average values 
will be used for the quantitative comparisons of laboratory experiments and previous studies because detailed spacial differences were not measured in the laboratory experiments.

Considering the volume of the dense water on the sloping bottom allows the ratio of source water $(R)$ in the rotating tank experiments to be written as

$$
\mathrm{R}=\frac{\mathrm{Q}}{\mathrm{Q}+w_{\mathrm{E}} \cdot A}
$$

where $\mathrm{Q}, w_{\mathrm{E}}$, and $A$ denote the flow rate of the dense source water, entrainment velocity, and the area of the dense water on the sloping bottom, respectively. Rewriting eq.(5.2) shows that the entrainment velocity $\left(w_{\mathrm{E}}\right)$ can be given as

$$
w_{E}=\frac{Q}{A} \frac{(1-R)}{R}
$$

The calculations for $w_{E}$ from eq.(5.3) and observed $U$ from the laboratory experiments give values for $E$ in the range of $1.2 \times 10^{-5}$ to $1.0 \times 10^{-3}$ as shown in Figure 5-1.

Smith (1975) used $e_{\circ}=E_{0} / l$, which is nearly the equivalent of $E$, as a nondimensional entrainment coefficient and gave values of $6.5 \times 10^{-4}$ and $1.0 \times 10^{-3}$ for the Norwegian overflow and the Mediterranean outflow, respectively. In Smith (1975) $E_{0}$ was defined by $E_{0} V=\int_{l^{-}}^{l^{+}} w_{e} d \eta$, where $V$ is the mean velocity, $l^{+}$and $l^{-}$denote the two edges of the overflow, $w_{e}$ is the entrainment velocity, and $\eta$ is the normal distance from the stream axis.

Approximate values for the entrainment parameter $(E)$ were calculated for the Denmark Strait overflow and the Mediterranean outflow based on observational studies to compare the results from the laboratory experiments with conditions in the ocean. Dickson and Brown (1994) reported that the Denmark strait overflow was initially $2.9 \times 10^{6} \mathrm{~m}^{3} \cdot \mathrm{sec}^{-1}$ and entrained $2.3 \times 10^{6} \mathrm{~m}^{3} \cdot \mathrm{sec}^{-1}$ while it traveled $160 \mathrm{~km}$ downstream. Using an approximate width of $100 \mathrm{~km}$ and a velocity of $30 \mathrm{~cm} \cdot \mathrm{sec}^{-1}$ for the overflow current, the entrainment parameter $(E)$ for the Denmark Strait overflow 
can be estimated using $\mathrm{Q}=2.9 \times 10^{6} \mathrm{~m}^{3} \cdot \mathrm{sec}^{-1}, \mathrm{R}=\frac{2.9}{2.9+2.3}, A=1.6 \times 10^{10} \mathrm{~m}^{2}$, and $U=30 \mathrm{~cm} \cdot \mathrm{sec}^{-1}$ in eqs.(5.1) and (5.3) to be $E=4.7 \times 10^{-5}$. The entrainment coefficient for the Mediterranean outflow will be estimated from the results presented in Baringer and Price (1997a). Using the estimate of entrainment for Section F, which was a cross section of the Mediterranean outflow approximately $140 \mathrm{~km}$ downstream of the outflow, with the initial Mediterranean outflow assumed to be $0.4 \times 10^{6}$ $\mathrm{m}^{3} \cdot \mathrm{sec}^{-1}$ using $\mathrm{Q}=0.4 \times 10^{6} \mathrm{~m}^{3} \cdot \mathrm{sec}^{-1}, \mathrm{R}=\frac{0.4}{0.4+0.83}, A=5.6 \times 10^{9} \mathrm{~m}^{2}$, and $\mathrm{U}=30 \mathrm{~cm} \cdot \mathrm{sec}^{-1}$ in eqs.(5.1) and (5.3) gives the estimate $E=1.5 \times 10^{-4}$. The estimate for $E$ obtained from the laboratory experiments bracket the values estimated from observational results in the two sill overflow regions (Figure 5-1).

Jungclaus and Backhaus (1994) showed the entrainment parameter (E) as a function of the friction coefficient $(r)$ and the Richardson number. The force balance for the experiments discussed in this thesis is based on the Coriolis force, viscosity, and density difference between the two layers, and does not include frictional forcing. However, comparisons are made tentatively assuming a value for a non-dimensional friction coefficient $(r)$. Figure 5-1 shows the values for $E$ from the laboratory experiments plotted against $r \cdot \mathrm{Fr}^{2}(=r / R i)$ with $r=0.01$ as in the numerical experiment including entrainment with the values of $E$ calculated in the model in Jungclaus and Backhaus (1994). The results from the laboratory experiments cover about two thirds of the solid line that represents the values for $E$ that was derived from numerical calculations using realistic scales for oceanic parameters, but the pattern the data points from the rotating tank experiments make does not match the line drawn in.

Özgökmen and Chassignet (2002) studied the mixing mainly in the head of gravity currents on a $1 \mathrm{~km}$ long sloping bottom with $5 \mathrm{~m}$ resolution and included a figure for $w_{\mathrm{E}} / \mathrm{B}^{1 / 3}$ plotted against slope angle. The buoyancy parameter (B) is defined as $B=g^{\prime} Q^{*}$, where $g^{\prime}$ is reduced gravity and $Q^{*}$ is the volume flux per unit width. Angles of 1, 2.5, and 5 degrees were used for the sloping bottom in the numerical experiments, and $w_{\mathrm{E}} / \mathrm{B}^{1 / 3}$ ranged between $7 \times 10^{-3}$ and $4.2 \times 10^{-2}$. Figure 5 -2 shows 


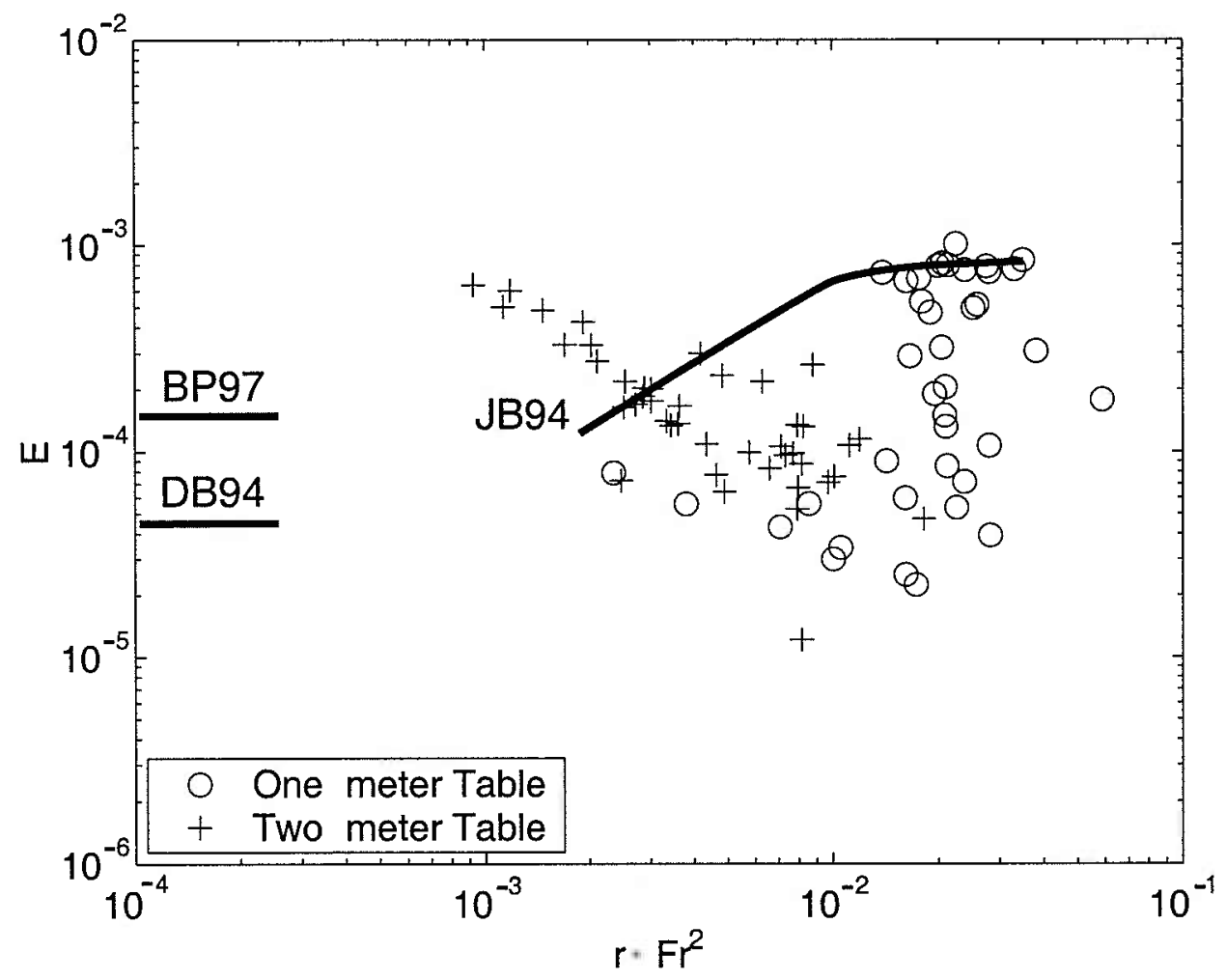

Figure 5-1: Entrainment parameter $\left(E=\mathcal{W}_{E} / \mathrm{U}\right)$ plotted against $r=\mathrm{Fr}^{2}$. The symbols $\circ$ and + are used for plotting the results from the experiments on the one-meter rotating table and the two-meter rotating table, respectively. The solid line labeled JB94 is drawn based on values calculated by the model in Jungclaus and Backhaus (1994). The short lines in the figure on the left labeled DB94 and BP97 indicate the values calculated for the Denmark Strait overflow and the Mediterranean outflow based on Dickson and Brown (1994) and Baringer and Price (1997a), respectively. 
the values for $w_{E} / B^{1 / 3}$ from the laboratory experiments on the one-meter rotating table plotted against the slope angle. Figure 5-2 shows that the slope angle for the laboratory experiments were between 5 and 35 degrees, but $w_{E} / B^{1 / 3}$ was smaller compared to the results presented in Özgökmen and Chassignet (2002). This is likely due to the difference in the speed of the head of the gravity current, where the numerical simulations by Özgökmen and Chassignet (2002) produced $1 \mathrm{~m} \cdot \mathrm{sec}^{-1}$ and the laboratory experiments gave about $1 \mathrm{~cm} \cdot \mathrm{sec}^{-1}$. The results from the experiments on the two-meter rotating table were not included because the slope was set to $\mathrm{s}=$ 0.2 and the data points did not provide information on the variability of $w_{\mathrm{E}} / \mathrm{B}^{1 / 3}$ depending on the slope angle.

\subsection{Connection to the Ocean}

The comparisons made in the preceding section between the laboratory experiments and previous studies show that the entrainment parameter $(E)$ from the experiments agree reasonably well with the conditions in the ocean. When $w_{E}$ is considered for a unit width, the r.h.s. of eq.(5.3) can be written as $U H(1-R) / L R$, where $H$ and L denote the layer thickness and the length of the bottom slope the overflow covers. Then, the entrainment parameter can be written as

$$
E=\frac{w_{E}}{U}=\frac{H}{L} \frac{(1-R)}{R}
$$

This conversion of $E$ based on eq.(5.3) was done so that the applicability of the experiments to the overflows in the deep ocean can be discussed based on observations for a cross section. In the deep ocean the overflows over sills generally have the scale of $\mathrm{H} \sim 100 \mathrm{~m}$ and $\mathrm{L} \sim 1000 \mathrm{~km}$. If $R$ changes between 0.01 and $0.99,(1-R) / R$ will range between 0.01 and 100 , giving values between $10^{-6}$ and $10^{-2}$ for $E$. The values for the entrainment parameter from the laboratory experiments $\left(1.2 \times 10^{-5}<E<\right.$ $1.0 \times 10^{-3}$ ) correspond to cases where $R$ is between 0.03 and 0.83 for the deep ocean, 


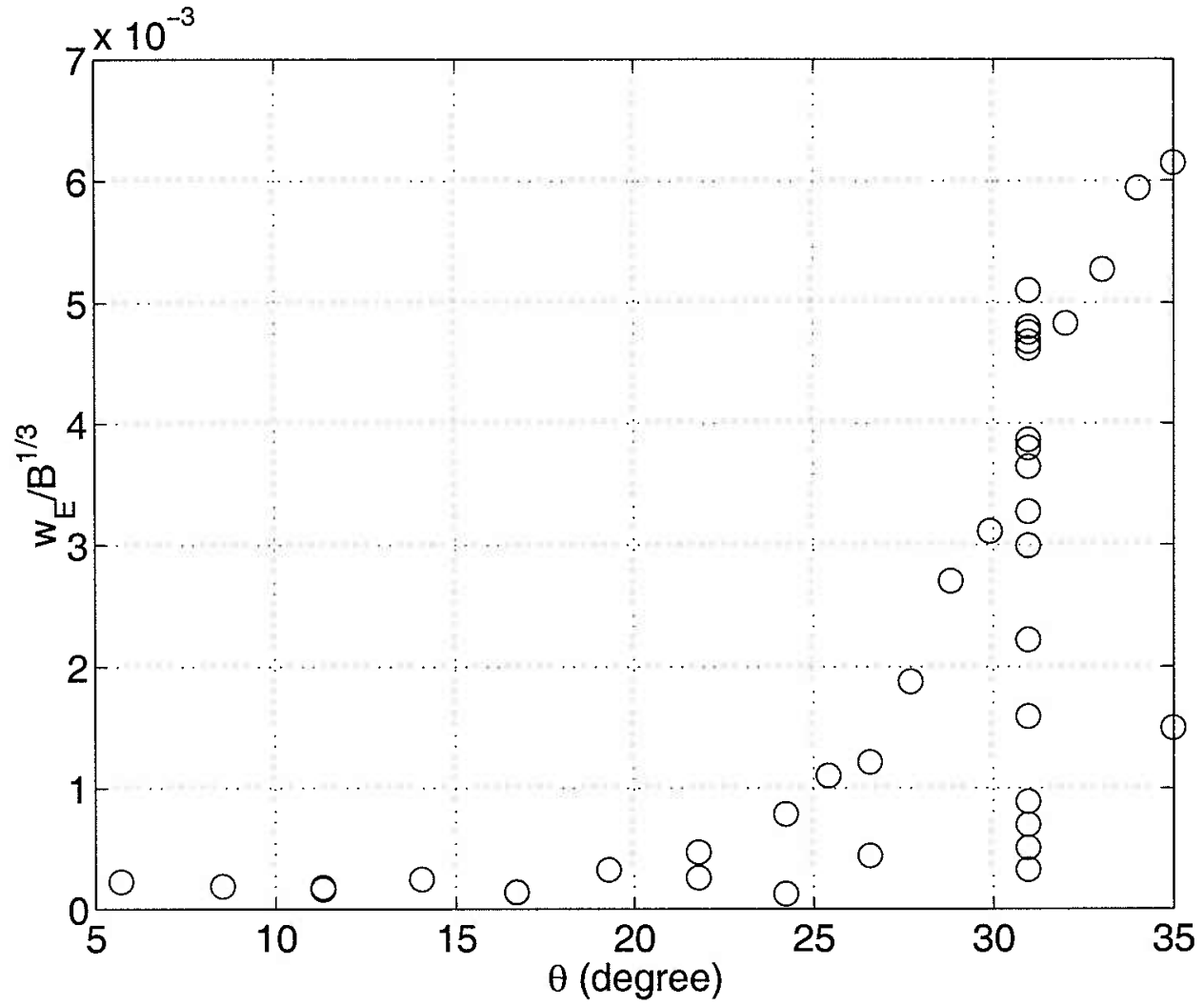

Figure 5-2: The ratio of Entrainment velocity $\left(w_{E}\right)$ to the power of $1 / 3$ of buoyancy (B) plotted against slope angle $(\theta)$ following Özgökmen and Chassignet (2002). 
and this shows that there is the possibility that the waves observed in the laboratory experiments could also be observed in the overflows in the ocean.

A nondimensional parameter can be formed using the adjustable parameters in the experiment as a power of $Q f^{5} g^{\prime-3} s^{-3}$, where $Q, f, g^{\prime}$, and $s$ denote the flow rate of the source water, rotation, reduced gravity, and slope. This combination of parameters can be rewritten as

$$
\frac{Q f^{5}}{g^{\prime 3} s^{3}}=\left(\frac{f H}{U}\right) \cdot\left(\frac{f W_{s}}{U}\right),
$$

using $U=g^{\prime} s / f$ and $Q=U H W_{s}$, where $U, H$, and $W_{s}$ denote the speed of the flow, the thickness of the dense layer, and the width of the source. The Inclusion of other variables such as viscosity and slope length would complicate the analysis. A nondimensional parameter

$$
\Pi=\left(\frac{Q f^{5}}{g^{\prime 3} s^{3}}\right)^{1 / 5}
$$

was defined to compare the experiments to the observational studies. Figure 5-3 plots $E$ against $\Pi$ for the data from the experiments on the one-meter rotating table and the two-meter rotating table. Data points from observations are shown using star symbols in Figure 5-3. The Denmark Strait overflow is indicated by DB94 based on the data from Dickson and Brown (1994), and the Mediterranean outflow is indicated by BP97 based on Baringer and Price (1997a). The star for the Denmark Strait overflow is located between two points that are for laminar flows, and the star for the Mediterranean outflow is located among points for flows in the wave regime. The star for observational values occupying a similar position in the figure as the data points for laboratory values that had waves in the gravity current suggests that waves might be present also in the ocean where there is overflow. 


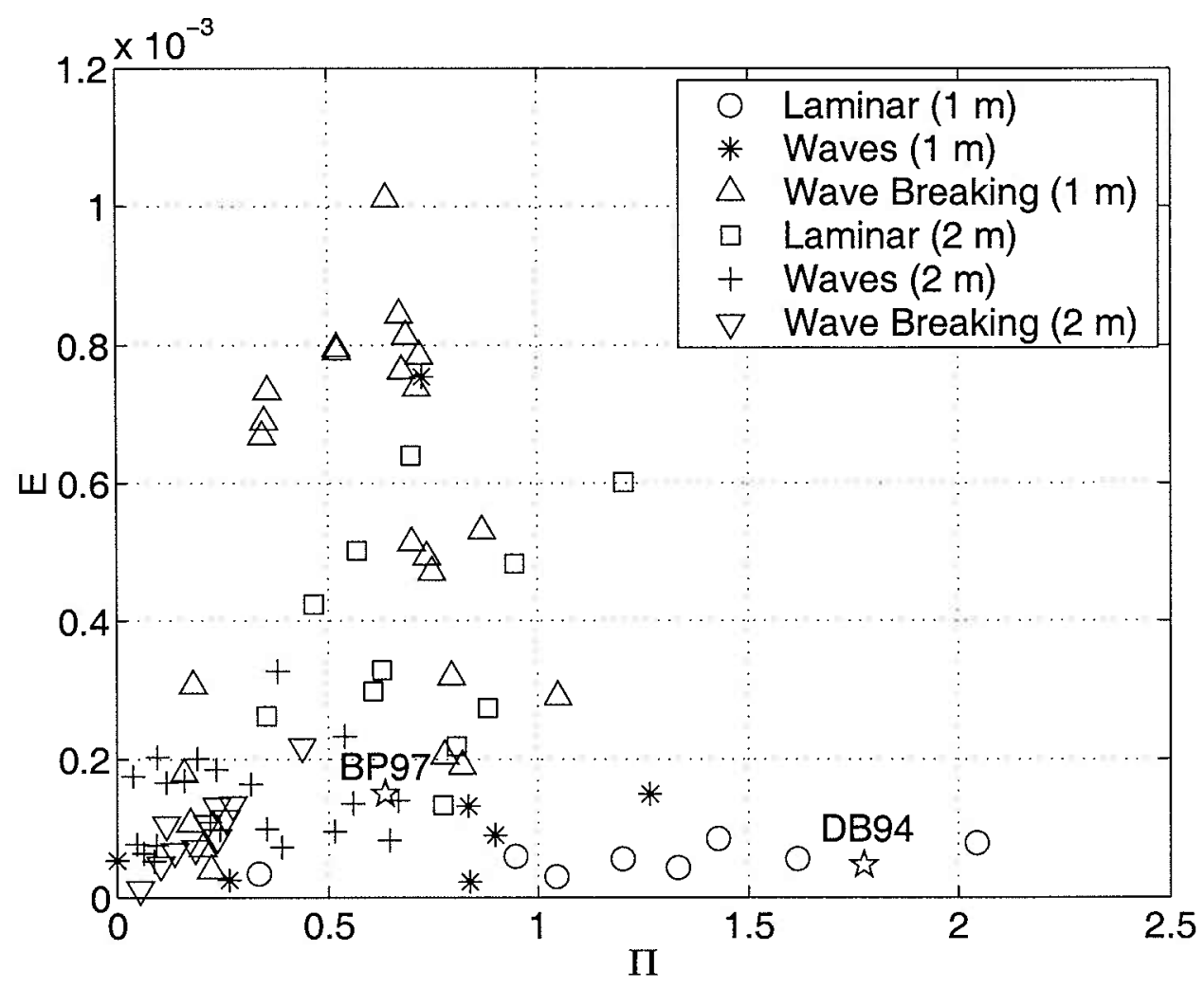

Figure 5-3: Relation between the entrainment parameter (E) and a nondimensional parameter $\Pi=\left(Q f^{5} g^{\prime-3} s^{-3}\right)^{1 / 5}$ for the experiments on the one-meter rotating table and the two-meter rotating table. The entrainment parameter is plotted against the nondimensional parameter $\Pi$ for the flows in the laminar regime (o), for the flows in the wave regime (*), and for the flows in the wave regime with waves breaking $(\triangle)$ for the one-meter rotating table, and for the flows in the laminar regime ( $\square$ ), for the flows in the wave regime $(+)$, and for the flows in the wave regime with waves breaking $(\nabla)$ for the two-meter rotating table. Values for the Denmark Strait overflow and the Mediterranean outflow are plotted in the figure using stars based on Dickson and Brown (1994) (noted as DB94 in the figure) and Baringer and Price (1997a) (noted as BP97), respectively. 


\subsection{Recommendations}

This study has explored a wide range of parameter setting for the rotation rate and reduced gravity. To carry out laboratory experiments to further understand the mixing on a sloping bottom in a rotating fluid, the reader may be motivated to study a wider range of slope angle and flow rate of the source water. A smaller slope $(s<0.1)$ will allow the gravity current to descend the sloping bottom slower and should be able to elucidate the effect of diffusion. A larger slope $(s>1)$ will cause the fluid to be turbulent and allow the departure of the fluid from the sloping bottom. Combining the results from these two sets of experiments should further clarify the contribution of diffusion and turbulence to the total mixing. The source tubing must be modified before studying the mixing for lower flow rates. The consistency of the experiments will be sacrificed, but the diameter of the tubing should be changed depending on the flow rate so that there will be no mixing within the tubing before the source water reaches the sloping bottom. A lower flow rate will allow the tubing used for connecting the flow meter and the source to be smaller, so a smaller plug could be used to hold back the dense fluid during the spin-up time. A smaller plug will be easily opened when the experiments are to be started, and could be placed in the tubing near the surface of the ambient water so that there will be less intrusion of ambient water in the source tubing during the spin-up. 


\section{Bibliography}

[1] Bainbridge, A.E., 1980, Geosecs Atlantic expedition, Vol. 2, Sections and Profiles 1972-1973, National Science Foundation, Washington D.C.

[2] Baringer, M.O., and J.F. Price, 1997a, Mixing and spreading of the Mediterranean outflow. J. Phys. Oceanogr., 27, 1654-1677.

[3] Baringer, M.O., and J.F. Price, 1997b, Momentum and energy balance of the Mediterranean outflow. J. Phys. Oceanogr., 27, 1678-1692.

[4] Britter, R.E., and P.F. Linden, 1980, The motion of the front of a gravity current traveling down an incline. J. Fluid Mech., 88, 223-240.

[5] Cenedese, C., J.A. Whitehead, T. Ascarelli, and M. Ohiwa, 2002, A rotating dense current down a slope. Submitted.

[6] Dickson, R.R., and J. Brown, 1994, The production of North Atlantic Deep Water: sources, rates, and pathways. J. Geophys. Res., 99, 12319-12341.

[7] Etling, D., F. Gelhardt, U. Schrader, F. Brennecke, G. Kühn, G.C. d'Hieres, and H. Didelle, 2000, Experiments with density currents on a sloping bottom in a rotating fluid. Dyn. Atmos. Oceans, 31, 139-164.

[8] Jiang, L, and R.W. Garwood Jr., 1996, Three-dimensional simulations of overflows on continental slopes. J. Phys. Oceanogr., 26, 1214-1233. 
[9] Jungclaus, J.H., and J.O. Backhaus, 1994, Application of a transient reduced gravity plume model to the Denmark Strait overflow. J. Geophys. Res., 99, 1237512396.

[10] Lane-Serff, G.F., and P.G. Baines, 1998, Eddy formation by dense flows on slopes in a rotating fluid. J. Fluid Mech., 363, 229-252.

[11] Middleton, G.V., 1966, Experiments on density and turbidity currents. Can. J. Earth. Sci., 3, 523-546.

[12] Nagata, Y., R. Kimura, H. Honji, Y. Yamazaki, K. Kawaguchi, and T. Hosoyamada, Laboratory experiments of dense water descending on continental slope, in Deep Ocean Circulation: Physical and Chemical Aspects, T. Teramoto, Ed., Elsevier Science Publishers, B.V.

[13] Özgökmen, T.M., and E.P. Chassignet, 2002, Dynamics of two-dimensional turbulent bottom gravity currents. J. Phys. Oceanogr., 32, 1460-1478.

[14] Pederson, B., 1980, Dense bottom currents in rotating ocean. J. Hydraul. Div., 106, 1291-1308.

[15] Pedlosky, J, 1986, Geophysical Fluid Dynamics, 2nd Ed., Springer-Verlag, New York.

[16] Pickard, G.L., and W.J. Emery, 1990, Descriptive Physical Oceanography - An Introduction, 5th ed., Butterworth-Heinemann, Oxford, UK.

[17] Price, J.F., and M.O. Baringer, 1994, Overflows and deep water production by marginal seas. Progress in Oceanography, 33, 161-200.

[18] Simpson, J.E., 1997, Gravity currents in the environment and the laboratory, 2nd Ed., Cambridge University Press, Cambridge, UK. 
[19] Smith, P.C., 1975, A streamtube model for bottom boundary currents in the ocean. Deep-Sea Res., 22, 853-873.

[20] Smith, P.C., 1977, Experiments with viscous source flows in rotating systems. Dyn. Atmos. Oceans, 1, 241-272.

[21] Sverdrup, H.U., M.W. Johnson, and R.H. Fleming, 1942, The Oceans: Their Physics, Chemistry, and General Biology. Prentice-Hall, Englewood Cliffs, New York.

[22] Weast, R.C. ed., 1984, CRC Handbook of chemistry and physics, 65th ed., CRC Press, Inc., Boca Raton, Florida.

[23] Whitehead, J.A., M.E. Stern, G.R. Flierl, and B.A. Klinger, 1990, Experimental observations of baroclinic eddies on sloping bottom. J. Geophys. Res., 95C, 95859610.

[24] Worthington, and W.R. Wright, 1970, North Atlantic Atlas of potential temperature and salinity in the deep water, including temperature, salinity, and oxygen profiles from the Erika Dan cruise of 1962. Woods Hole Oceanographic Institution Atlas Ser. Vol. 2, Woods Hole, Massachusetts. 